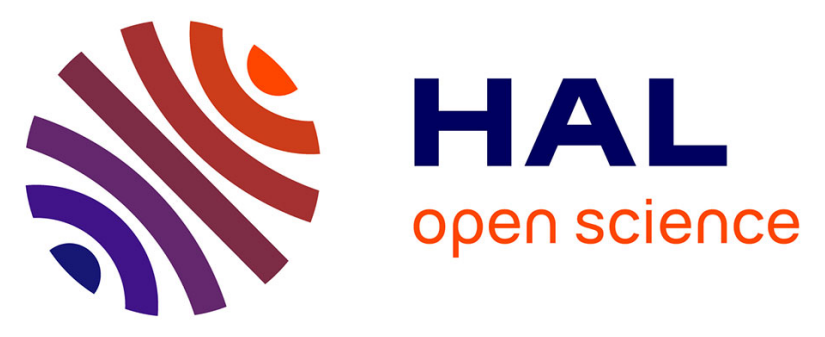

\title{
Oxygen (3P) atom recombination on a Pyrex surface in an $\mathrm{O} 2$ plasma
}

\author{
Jean-Paul Booth, Olivier Guaitella, Abhyuday Chatterjee, Cyril Drag, V. \\ Guerra, Dmitry Lopaev, Sergey Zyryanov, Tatyana Rakhimova, Dmitry \\ Voloshin, Y. Mankelevich
}

\section{To cite this version:}

Jean-Paul Booth, Olivier Guaitella, Abhyuday Chatterjee, Cyril Drag, V. Guerra, et al.. Oxygen (3P) atom recombination on a Pyrex surface in an O2 plasma. Plasma Sources Science and Technology, 2019, 28 (5), pp.055005. 10.1088/1361-6595/ab13e8 . hal-02272108

\section{HAL Id: hal-02272108 https://hal.science/hal-02272108}

Submitted on 22 Nov 2019

HAL is a multi-disciplinary open access archive for the deposit and dissemination of scientific research documents, whether they are published or not. The documents may come from teaching and research institutions in France or abroad, or from public or private research centers.
L'archive ouverte pluridisciplinaire HAL, est destinée au dépôt et à la diffusion de documents scientifiques de niveau recherche, publiés ou non, émanant des établissements d'enseignement et de recherche français ou étrangers, des laboratoires publics ou privés. 


\title{
Oxygen $\left({ }^{3} \mathrm{P}\right)$ atom recombination on a Pyrex surface in an $\mathrm{O}_{2}$ plasma
}

\author{
J.P. Booth ${ }^{1}$, O. Guaitella ${ }^{1}$, A. Chatterjee ${ }^{1}$, C. Drag ${ }^{1}$, V. Guerra ${ }^{2}$,

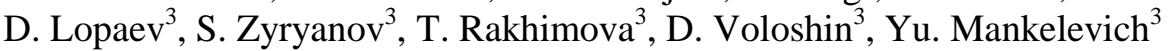 \\ ${ }^{l}$ Laboratoire de Physique des Plasmas, CNRS, Ecole Polytechnique, UPMC Univ Paris 06, Univ Paris-Sud, France \\ ${ }^{2}$ Instituto de Plasmas e Fusão Nuclear, Instituto Superior Técnico, Universidade de Lisboa, Portugal \\ ${ }^{3}$ Skobeltsyn Institute of Nuclear Physics, Lomonosov Moscow State University, Russian Federation
}

\begin{abstract}
The recombination of $\mathrm{O}\left({ }^{3} \mathrm{P}\right)$ atoms on the surface of a Pyrex tube containing a DC glow discharge in pure $\mathrm{O}_{2}$ was studied over a wide range of pressure (0.2-10 Torr) and discharge current (10-40 mA) for two fixed surface temperatures $\left(+50^{\circ} \mathrm{C}\right.$ and $\left.+5^{\circ} \mathrm{C}\right)$. The recombination probability, $\gamma$, was deduced from the observed atom loss rate (dominated by surface recombination) determined by time-resolved optical emission actinometry in partially-modulated (amplitude $~ 15-17 \%$ ) discharges. The value of $\gamma$ increased with discharge current at all pressures studied. As a function of pressure it passes through a minimum at $\sim 0.75$ Torr. At pressures above this minimum $\gamma$ is well-correlated with the gas temperature, $\mathrm{T}_{\mathrm{g}}$, (determined from the rotational structure of the $\mathrm{O}_{2}\left(\mathrm{~b}^{1} \Sigma_{\mathrm{g}}{ }^{+}, \mathrm{v}=0\right) \rightarrow \mathrm{O}_{2}\left(\mathrm{X}^{3} \Sigma_{\mathrm{g}}{ }^{-}, \mathrm{v}=0\right)$ emission spectrum) which increases with pressure and current. The temperature of the atoms incident at the surface was deduced from a model, calibrated by measurements of the spatially-averaged gas temperature and validated by radial temperature profile measurements. The value of $\gamma$ follows an Arrhenius law depending on the incident atom temperature, with an activation energy in the range $0.13-0.16 \mathrm{eV}$. At the higher surface temperature the activation energy is the same, but the pre-exponential factor is smaller. Under conditions where the $\mathrm{O}$ flux to the surface is low $\gamma$ falls below this Arrhenius law. These results are well explained by an Eley-Rideal (ER) mechanism with incident $O$ atoms recombining with both chemisorbed and more weakly bonded physisorbed atoms on the surface, with the kinetic energy of the incident atoms providing the energy to overcome the activation energy barrier. A phenomenological Eley-Rideal model is proposed that explains both the decrease in recombination probability with surface temperature as well as the deviations from the Arrhenius law when the $\mathrm{O}$ flux is low. At pressures below 0.75 Torr $\gamma$ increases significantly, and also increases strongly with the discharge current. We attribute this effect to incident ions and fast neutrals arriving with sufficient energy to clean or chemically modify the surface, generating new adsorption sites. Discharge modeling confirms that at pressures below $\sim 0.3$ Torr a noticeable fraction of the ions arriving at the surface have adequate kinetic energy to break surface chemical bonds (> 3-5 $\mathrm{eV})$.
\end{abstract}

Keywords: atom surface recombination, $\mathrm{O}$ atoms, $\mathrm{O}_{2}$ plasma

\section{Introduction}

Oxygen gas is widely used in many plasma processing applications, and oxygen atoms are one of the key reactive species present in them, leading to recurrent interest in $\mathrm{O}$ atom kinetics over a range of different discharge conditions. In low-pressure pure oxygen plasmas these atoms are principally created by electron impact dissociation of $\mathrm{O}_{2}$, and predominantly lost by surface recombination; therefore these two processes define the atom density in the plasma volume [1-12]. The surface recombination of $O$ atoms has been previously studied on a range of different materials, including dielectrics, semiconductors and metals [1-12]. In the majority of cases only the global $\mathrm{O}$ atom loss probability was measured. However, the values reported often vary widely even for the same material and under apparently similar conditions. Several studies have investigated the dependence on surface temperature, allowing the activation energy to be estimated $[1,4,5,7,8,9,11]$; however, the effect of gas temperature, which may not be in equilibrium with the surface temperature, has been ignored up to now. No universal model to describe all these data has been formulated to date. Both the chemical composition and the structure of the surface can have a large effect on the reaction rate. Even small surface modifications, arising from details of the material fabrication or processing, adsorption of reactive species, as well as contamination, can lead to irreversible changes in the surface reaction sites and therefore the atom loss probability.

Despite the wide variety of experimental conditions, a commonly-accepted view of the atom recombination processes has emerged. Atom surface recombination is generally understood to occur via two mechanisms, depending on whether the recombination probability depends on the atom concentration 
to first order (Eley-Rideal mechanism) or second order (Langmuir-Hinshelwood mechanism) [1,3,5,8,9,13-16]. In the Eley-Rideal (ER) mechanism, an atom arriving at the surface directly recombines with an absorbed (either chemisorbed or physisorbed) atom. In the case of physisorbed atoms the surface plays an analogous role to the third body in volume three-body recombination processes [17-23]. In contrast, in the Langmuir-Hinshelwood (LH) mechanism, physisorbed atoms diffuse long distances across the surface before recombining with a chemisorbed atom (and also with physisorbed atoms if their surface density is high enough). The LH mechanism becomes dominant at lower temperatures (below $250 \mathrm{~K}[1,8,15,19,20])$, where the rate of desorption of physisorbed atoms is slow, leading to long average surface diffusion lengths. At temperatures above room-temperature the ER mechanism is generally dominant.

It might be expected that the atom surface loss probability would be almost constant for a given material and surface temperature. However, plasma-exposed surfaces are exposed to fluxes of energetic particles, including photons, ions accelerated across the sheath (to several $\mathrm{eV}$ or more), and even fast neutrals created from ions by charge-exchange reactions. These species can have sufficient energy to break the bonds on the surface, and potentially influence the atom recombination. Processes occurring inside the plasma (gas heating and chemical reactions) can also affect the energy distribution of atoms arriving at the surface. However, the effect of the kinetic energy of atoms arriving at the surface on their recombination probability has not been considered previously.

This paper is devoted to the study of the recombination of $\mathrm{O}$ atoms on a Pyrex surface in an $\mathrm{O}_{2}$ plasma. The experiments were carried out in DC discharge in a long Pyrex tube. A wide range of plasma conditions (current, pressure and surface temperature) were studied, allowing the effects of different factors (wall temperature, gas temperature, the atom flux to the walls, and ion flux and energy) to be investigated. The paper is organized as follows. The experimental details are described in Section 2. The discharge model used to obtain the radial gas temperature profile is presented in Section 3. Section 4 presents the technique used to measure the $\mathrm{O}$ atom loss frequency. Section 5 presents the experimental results with a discussion. A model of the Eley-Rideal recombination process is presented in Section 6 . The results at pressures below 0.75 Torr are presented in section 7 .

\section{Experimental setup and data analysis}

\subsection{Discharge tube}

The experimental setup is shown in figure 1. A DC glow discharge in $\mathrm{O}_{2}$ (with the addition of 5\% Ar for the actinometry measurements) was ignited in a Pyrex tube of $20 \mathrm{~mm}$ inner diameter and 560mm length. The tube surface is kept at a constant temperature by a water/ethanol mixture flowing through an outer envelope and connected to a thermostatic bath. The temperature drop across the Pyrex tube wall was considered to be negligible (assuming a linear power loading of $\mathrm{P}=1 \mathrm{~W} / \mathrm{cm}$, a thermal conductivity of $0.0136 \mathrm{~W} /(\mathrm{cm} \cdot \mathrm{K})$ and a thickness of $0.2 \mathrm{~cm}$, the temperature drop across the tube wall will be less than 2 $\mathrm{K})$. The distance between the hollow cathode electrodes (in side-arms) is $\sim 500 \mathrm{~mm}$. The anode is connected to a positive polarity high-voltage power supply via a non-inductive $68 \mathrm{k} \Omega$ ballast resistor, and the cathode is connected to ground via a non-inductive $15 \mathrm{k} \Omega$ resistor. The gas flow rate was kept low (3 sccm for pressures $<1$ Torr and $10 \mathrm{sccm}$ for pressure $>1$ Torr) so as to ensure that the gas residence time (>1 second) is longer than the lifetime of all active species in discharge, notably $\mathrm{O}\left({ }^{3} \mathrm{P}\right)$ atoms and metastable $\mathrm{O}_{2}\left(\mathrm{a}^{1} \Delta_{\mathrm{g}}\right)$ molecules. The leak rate of air into the system was less than $\sim 0.015 \mathrm{sccm}$, corresponding to less than $0.4 \% \mathrm{~N}_{2}$ in the mixture in the worst case. Such a nitrogen concentration is not expected to have any noticeable effect on the $\mathrm{O}$ atom kinetics, either in the gas phase or on the surface. In this way a uniform plasma column is created with constant gas composition and plasma parameters between the electrodes. Nevertheless, heating of the gas by the discharge creates a significant radial gradient in gas temperature (see below), resulting in a radial gradient in gas density. However, since the $\mathrm{O}\left({ }^{3} \mathrm{P}\right)$ surface loss probability is small, and assuming gas phase recombination to be negligible, the $\mathrm{O}\left({ }^{3} \mathrm{P}\right)$ molar fraction will be constant across the radius, allowing the loss probability to be estimated from the pulsed kinetic measurements with no need to correct for a diffusion gradient.

For the kinetic measurements the discharge current was partially modulated by short-circuiting (using a MOSFET transistor) the $15 \mathrm{k} \Omega$ resistor ballast resistor connecting the cathode to ground. This results in square-wave modulation of the current with an amplitude of $\sim 15-17 \%$ (varying slightly due to variation of the plasma resistance). A period of $292 \mathrm{~ms}$ with a $50 \%$ duty circle was used in all measurements. 


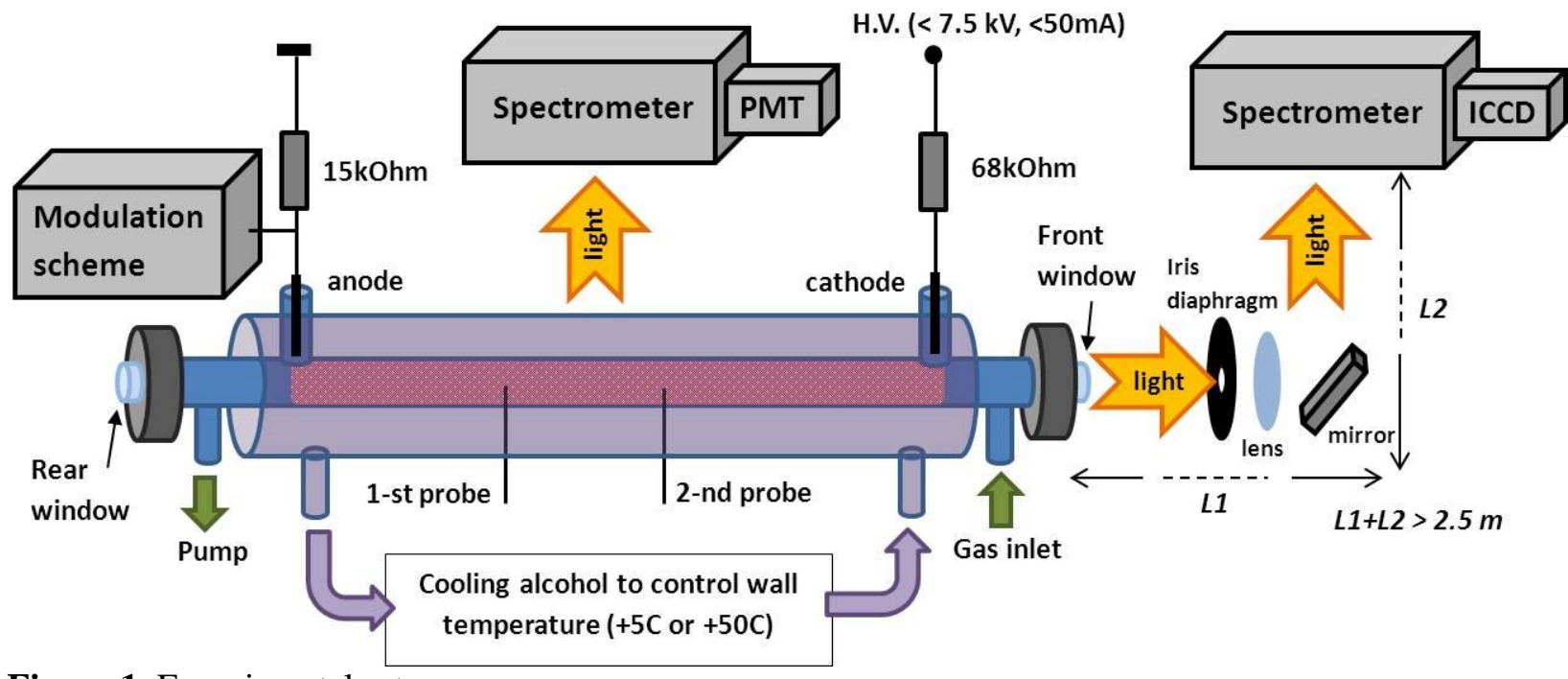

Figure 1. Experimental setup.

\subsection{Electric field measurement}

The use of actinometry to follow the temporal behavior of the atom density during current modulation is only valid if the rates of atom excitation by electron impact does not vary significantly during the period. These rates depend on the electron energy distribution function, in turn determined by the reduced electric field, Furthermore, the value of the reduced electric field is needed to verify the model, used to deduce the gas temperature radial profile. The longitudinal electric field, $\mathrm{E}_{\mathrm{z}}$, was determined from the space potential measured at two axial positions (separated by $\sim 200 \mathrm{~mm}$ ) using floating, high-impedance (0.5 G $\Omega$ ) electrostatic probes (tungsten $\sim 0.5 \mathrm{~mm}$ diameter) inserted through the sidewall. We assume that $\mathrm{E}_{\mathrm{z}}$ is constant across the tube radius. In figure $2 \mathrm{E}_{\mathrm{z}}$ is shown as a function of the $\mathrm{O}_{2}$ pressure for different discharge currents, with a wall temperature $\mathrm{T}_{\mathrm{w}}=+50^{\circ} \mathrm{C}$. At $\mathrm{T}_{\mathrm{w}}=+5^{\circ} \mathrm{C}$ the electric field is slightly higher (by 2-4\%). Figure 2 also shows the values of $\mathrm{E}_{\mathrm{z}}$ predicted by the model, discussed below in Section 3 .

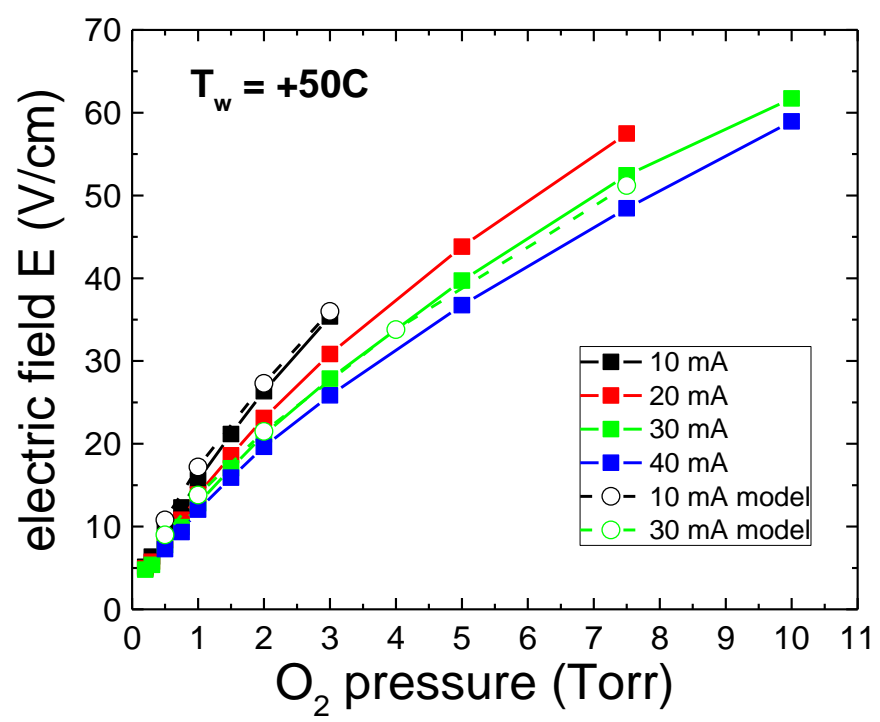

Figure 2. Electric field in the positive column of the dc discharge as a function of the $\mathrm{O}_{2}$ pressure for different currents at $\mathrm{T}_{\mathrm{w}}=+50^{\circ} \mathrm{C}$. The dark symbols and solid lines are experimental data. The open symbols and dashed lines are the results of the self-consistent model (see text). 


\subsection{Gas temperature measurement}

The gas temperature was determined from the rotational structure of the $\mathrm{O}_{2}\left(\mathrm{~b}^{1} \Sigma_{\mathrm{g}}{ }^{+}, \mathrm{v}=0\right) \rightarrow\left(\mathrm{X}^{3} \Sigma_{\mathrm{g}}{ }^{-}, \mathrm{v}=0\right)$ optical emission at $762 \mathrm{~nm}$ [24-26]. The light emission from the plasma was observed in two different ways. In the first configuration, light was collected perpendicular to the tube axis (mid-way between the electrodes) with a collimating lens, and focused with a second lens into a spectrometer (Princeton IsoPlane SCT-320). This configuration gives a measurement, $\mathrm{T}_{\mathrm{g}_{\mathrm{a}} \text { ver, }}$, averaged across the tube radius (but weighted by the radial density profile of the emitting $\mathrm{O}_{2}\left(\mathrm{~b}^{1} \Sigma_{\mathrm{g}}^{+}\right)$). The light at the exit slit of the spectrometer was detected with an IR-sensitive photomultiplier (Hamamatsu H7422P-50) and the spectra recorded by scanning the diffraction grating, giving low-noise, high-quality spectra. The temperature was deduced by fitting a simulated spectrum to the observed $\mathrm{P}$ branch spectra, giving an accuracy better than $\pm 5^{\circ} \mathrm{C}$. Examples of the observed $\mathrm{O}_{2}\left(\mathrm{~b}^{1} \Sigma_{\mathrm{g}}{ }^{+}, \mathrm{v}=0\right) \rightarrow\left(\mathrm{X}^{3} \Sigma_{\mathrm{g}}{ }^{-}, \mathrm{v}=0\right)$ emission spectra are shown in figure 3 .

Figure 4 presents the measured average gas temperature, $\mathrm{T}_{\mathrm{g}_{\_} \text {aver }}$, as a function of linear discharge power, $E_{z} J_{d}$, where $E_{z}$ and $J_{d}$ are the measured electric field and discharge current, respectively. For a given power the gas temperature was independent of the gas pressure (over the range studied) and increased slightly less than linearly with the discharge power. As expected, the gas temperature also increases with the wall temperature, since the dominant loss of thermal energy is thermal accommodation at the walls. The observed shift of the fitted $\mathrm{T}_{\mathrm{g} \_ \text {aver }}$ curves between wall temperatures of $+5^{\circ} \mathrm{C}$ and $+50^{\circ} \mathrm{C}$ is $\sim 43 \pm 2^{\circ} \mathrm{C}$, agreeing well with the wall temperature difference of $45^{\circ} \mathrm{C}$. Also shown are the results from the model (described in section 3); the full triangles are with a thermal accommodation coefficient $\alpha=0.3$, and the full squares use $\alpha=0.67$. The model using an accommodation coefficient $\alpha=0.3$ fits the experimental data very well, whereas using a value of $\alpha=0.67$ (commonly used in the literature $[27,28]$ ) gives much poorer agreement.

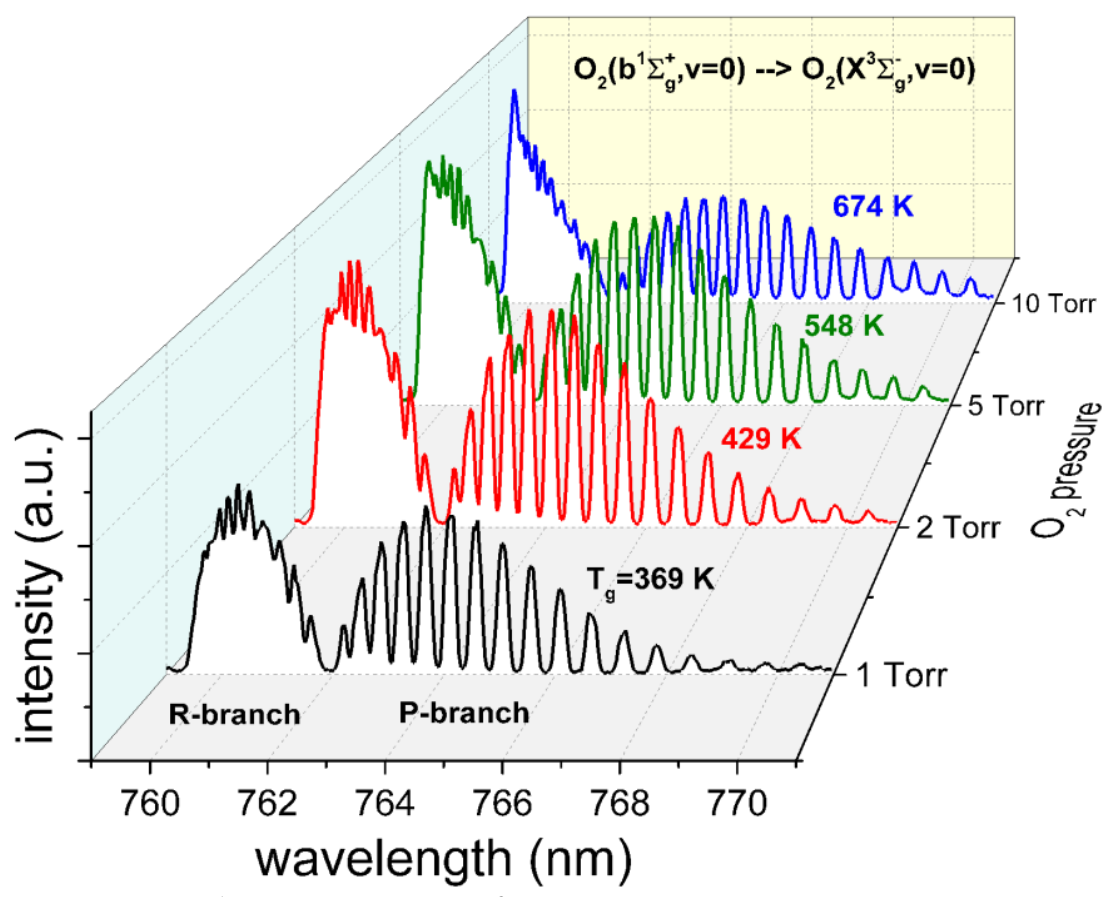

Figure 3. Examples of the $\mathrm{O}_{2}\left(\mathrm{~b}^{1} \Sigma_{\mathrm{g}}{ }^{+}, \mathrm{v}=0\right) \rightarrow \mathrm{O}_{2}\left(\mathrm{X}^{3} \Sigma_{\mathrm{g}}{ }^{-} \mathrm{v}=0\right)$ emission spectra for different discharge conditions, along with the fitted gas temperature. 


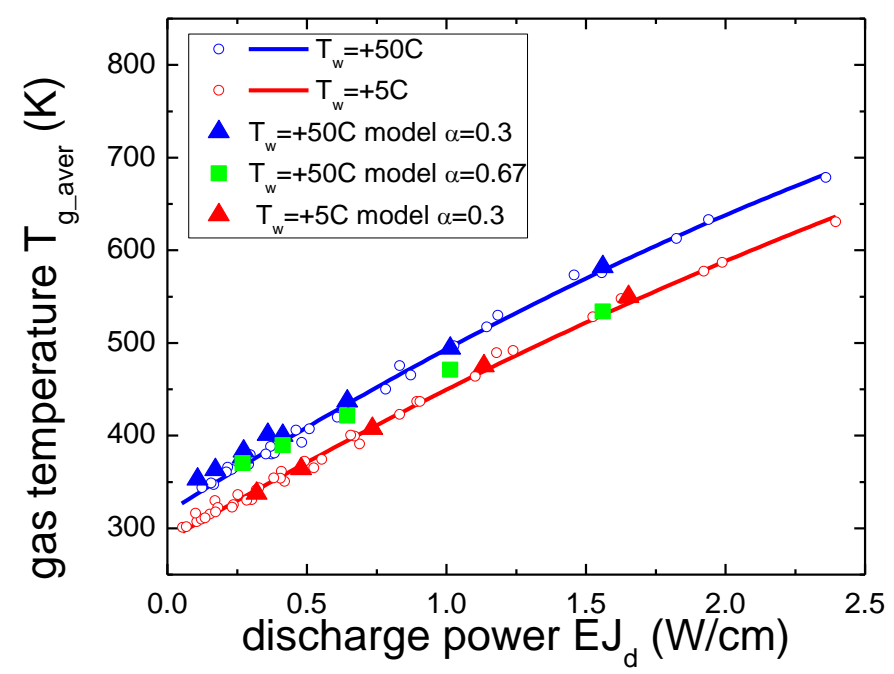

Figure 4. Radially-averaged gas temperature $\mathrm{T}_{\mathrm{g} \_a v e r}$, determined from the $\mathrm{O}_{2} \mathrm{~b}$ emission spectrum, as a function of the linear discharge power $\mathrm{EJ}_{\mathrm{d}}$ dissipated in the positive column of the $\mathrm{O}_{2}$ glow discharge. The open circles are experimental data, the triangles are the results of the model using a accommodation coefficient of $=\alpha=0.3$, and the green squares with $\alpha=0.67$ respectively.

In the second measurement configuration, light emitted along the discharge axis was observed via a $15 \mathrm{~mm}$ diameter window at the end of the tube. An image of the discharge cross-section (with the focal plane about $10 \mathrm{~cm}$ behind the window, although the depth-of-field is large) was created at the entrance slit of the spectrograph (situated at $\sim 2.7 \mathrm{~m}$ from the window) using a $70 \mathrm{~cm}$ FL lens ( $2 \mathrm{~F}: 2 \mathrm{~F}$ configuration, see figure 1). The spectrograph is aberration-corrected, producing a $2 \mathrm{D}$ image at the output plane, spectrally dispersed in the horizontal plane and spatially resolved (across the discharge diameter) in the vertical plane. The output image was recorded using a 2D intensified CCD detector (Princeton PI-MAX 4), allowing emission spectra to be simultaneously recorded for different radial positions, giving the radial distribution of gas temperature $\mathrm{T}_{\mathrm{g}}(\mathrm{r})$ with a spatial resolution of $1 \mathrm{~mm}$. However, the limited diameter of the end window $(15 \mathrm{~mm})$ prevented measurement all the way to the walls, making it necessary to use a model to estimate the actual temperature of the gas in contact with the Pyrex tube surface. Figure 5 shows the radial temperature profiles (solid symbols) determined by this method for a discharge current of $30 \mathrm{~mA}$ and for a range of gas pressures. Also shown (open symbols) are the $\mathrm{O}$ atom translational temperatures determined directly from High-resolution Two-photon Absorption Laser-Induced Fluorescence (HR TALIF) measurements of their Doppler profile, using the same laser set up as in Booth et al. [29]. Since this technique is time-consuming, and the error bars were somewhat bigger $( \pm 10 \mathrm{~K})$, the HR-TALIF measurements were only made at the tube axis and at one point centered at $1 \mathrm{~mm}$ from the wall (an end window allowing optical access to the complete tube radius was available in these later measurements). Nevertheless, the temperatures obtained by HR-TALIF are in excellent agreement (within the error bars) with the values from $\mathrm{O}_{2}\left(\mathrm{~b}^{1} \Sigma_{\mathrm{g}}^{+}\right)$emission.

The temperature profiles predicted by the model, using a thermal accommodation coefficient of 0.3 , are presented by solid lines in figure 5 . Above all it is worth noting the rather good agreement between the two sets of measurements and the model calculation. As expected, the temperature is maximal at the tube axis, dropping towards the walls where the thermal energy is lost by (partial) accommodation. This demonstrates the validity of the model, and justifies its utilization to derive the gas temperature in contact with the walls (and therefore the kinetic energy of atoms striking walls), where we could not make measurements.

The total gas number density, $\mathrm{N}$, was then calculated from the measured pressure and average gas temperature, $\mathrm{T}_{\mathrm{g} \_a \text { aver }}$, assuming the ideal gas law: $\mathrm{P}=\mathrm{Nk}_{\mathrm{B}} \mathrm{T}_{\mathrm{g} \_a \text { aver }}$. The value of the reduced electric field, $\mathrm{E} / \mathrm{N}$, could then be calculated. However, since the gas is hotter at the axis of the tube than close to walls, there is a concomitant radial gas density gradient, leading to a decrease of $\mathrm{E} / \mathrm{N}$ with radius. The biggest radial variations in $\mathrm{E} / \mathrm{N}$ occur at highest discharge power, corresponding to the highest pressures and currents. In the worst case, 10 Torr and $50 \mathrm{~mA}$, the value of E/N changes from $\sim 30 \mathrm{Td}$ near the wall to 
$\sim 53 \mathrm{Td}$ at the axis. However, for most discharge regimes the radial $\mathrm{E} / \mathrm{N}$ variations are notably smaller, and in most cases below 20-30\%.

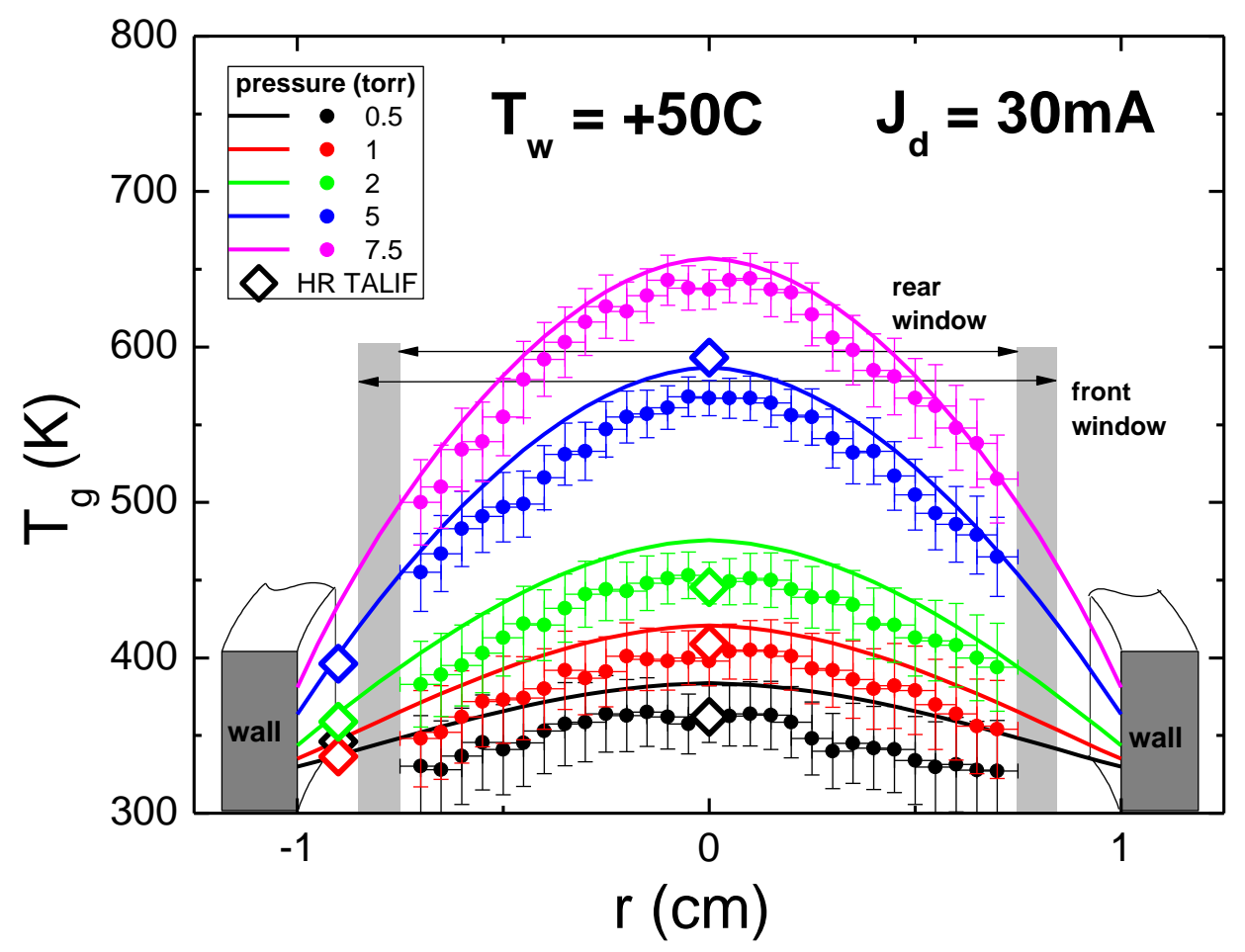

Figure 5. Measured radial profiles (symbols) of gas temperature $\mathrm{T}_{\mathrm{g}}(\mathrm{r})$ for a discharge current $30 \mathrm{~mA}$, a wall temperature $\mathrm{T}_{\mathrm{w}}=+50^{\circ} \mathrm{C}$ and for different pressures, compared to the model results (solid lines) assuming a thermal accommodation coefficient of 0.3 . The solid symbols represent temperature measurements by OES of the $\mathrm{O}_{2}\left(\mathrm{~b}^{1} \Sigma_{\mathrm{g}}{ }^{+} \mathrm{v}=0\right) \rightarrow\left(\mathrm{X}^{3} \Sigma_{\mathrm{g}}{ }^{-}, \mathrm{v}=0\right)$ emission, and the open symbols represent measurements by HR TALIF of $\mathrm{O}$ atoms.

\section{Discharge model and radial gas temperature profile}

The self-consistent $1 \mathrm{D}(\mathrm{r})$ model of the $\mathrm{O}_{2}$ dc discharge used here has been developed over several years at MSU [30,31,32]. Although it predicts all of the major internal parameters of the discharge (the results of which will be presented elsewhere), here we employ it only to deduce the gas temperature profiles. The model includes all major charged and neutral particles: electrons, negative ions $\left(\mathrm{O}^{-}, \mathrm{O}_{2}{ }^{-}\right.$and $\mathrm{O}_{3}{ }^{-}$), positive ions $\left(\mathrm{O}^{+}, \mathrm{O}_{2}{ }^{+}, \mathrm{O}_{3}{ }^{+}\right.$and $\mathrm{O}_{4}{ }^{+}$), vibrationally excited $\mathrm{O}_{2}(\mathrm{v})$ molecules ( $\mathrm{v}$ up to 40 ), metastable molecules $\left(\mathrm{O}_{2}\left(\mathrm{a}^{1} \Delta_{\mathrm{g}}\right), \mathrm{O}_{2}\left(\mathrm{~b}^{1} \Sigma_{\mathrm{g}}{ }^{+}\right)\right.$and $\mathrm{O}_{2}{ }^{*}$, an effective sum of the $\mathrm{O}_{2}$ Hertzberg states $), \mathrm{O}\left({ }^{3} \mathrm{P}\right)$ and $\mathrm{O}\left({ }^{1} \mathrm{D}\right)$ atoms and $\mathrm{O}_{3}$ molecules. The total reaction set has been presented previously [30,31,32]. The model includes continuity equations in the radial direction for the neutral and charged species, as well as the gas temperature. The charged species radial profiles are calculated assuming ambipolar diffusion, with selfconsistent calculation of the radial electric field such as to satisfy the quasi-neutrality condition. The Boltzmann equation is solved (using the two-term approximation) for each radial grid cell using the (modeled) local gas composition and the (measured) axial field $E_{z}$, providing the electron energy distribution function (EEDF), the electron drift velocity and the rate constants for various electron-impact reactions at each radial grid position.

The gas temperature $T(r, t)$ at constant pressure was found by solving the equations for the total gas enthalpy $H(r, t)$ :

$$
\begin{aligned}
& \frac{\partial H(r, t)}{\partial t}=j \cdot E-P_{r a d}+\frac{1}{r} \frac{\partial}{\partial r}\left(r \cdot \lambda \frac{\partial T}{\partial r}\right)+\sum_{i} h_{i} \cdot J_{D i} \\
& H(r, t)=\sum_{i} n_{i} \cdot h_{i}=\sum_{i} n_{i} \cdot\left(\int_{0}^{T} C_{P i}(T) d T+h_{f i}\right)
\end{aligned}
$$


where $j E_{z}$ is the Joule gas heating, $P_{r a d}$ is the energy loss by radiation, $\lambda(\mathrm{erg} /(\mathrm{cm} \cdot \mathrm{s} \cdot \mathrm{K}))=27.9 \cdot T^{0.8}$ is the thermal conductivity of oxygen gas, $h_{i} \cdot J_{D i}=-D_{i} \cdot N \cdot \nabla\left(n_{i} / N\right)$ is the energy flux due to diffusion of each species i of number density $n_{i}$, with enthalpy $h_{i}$ and heat capacity $C_{P i} . h_{f i}$ - is the standard enthalpy of formation of the $\mathrm{i}$-th component. The temperature dependence of the heat capacity was calculated from the polynomial approximation: $C_{p i}(T)=\Sigma a_{i j} \cdot T^{j}$, where $j=0-4$, using the coefficients for each species, $\mathrm{i}$, given in [33]. The wall temperature, $T_{w}$, was set to the experimental value (assuming no drop across the Pyrex tube, as discussed above). The temperature jump, $\delta \mathrm{T}=\mathrm{T}_{\mathrm{nw}}-\mathrm{T}_{\mathrm{w}}$, between the wall temperature, $\mathrm{T}_{\mathrm{w}}$, and the gas temperature in contact with it, $\mathrm{T}_{\mathrm{nw}}$, depends on the pressure $p$, the heat flux $F$ to the wall and the thermal accommodation coefficient, $\alpha$, of the gas particles hitting the tube surface (predominantly $\mathrm{O}_{2}$ molecules and $\mathrm{O}$ atoms, which we assume to have the same value of $\alpha$ ) [34]:

$$
\delta T \propto F \cdot T_{n w}^{0.5} \frac{2-\alpha}{\alpha \cdot p}
$$

This jump therefore is bigger for low accommodation coefficients, low pressure and high power. Accommodation coefficients are difficult to measure experimentally, and the value for $\mathrm{O} / \mathrm{O}_{2}$ mixtures is not known. Values in range $0.3 \leq \alpha \leq 0.67$ have been reported for various gases in the literature [27,28], so we have made simulations for these two extreme values.

The time-dependent equations for the particle number densities, $n_{i}(r, t)$, the EEDF, the gas temperature $T(r, t)$ and the axial electric field $E_{z}(t)$ were solved self-consistently until steady-state, setting the current as an input parameter. Simultaneous agreement with the measured gas temperature profiles and with the measured axial electric field were taken as the principal criteria for validity of the model, and therefore of the calculated radial gas temperature profiles. Examples of the calculated axial electric fields (figure 2) and average gas temperatures (figure 4) are compared to experiment for currents of 10 and 30 $\mathrm{mA}$ and wall temperature $+50^{\circ} \mathrm{C}$. Good agreement is only observed when an accommodation coefficient $\alpha=0.3$ is used. Using a larger value for $\alpha$ (as shown in figure 4 for $\alpha=0.67$ ) leads to poor agreement, underestimating the average gas temperature at high discharge power.

The measured and calculated radial temperature profiles are compared in figure 5 for $30 \mathrm{~mA}, \mathrm{~T}_{\text {wall }}$ $=+50^{\circ} \mathrm{C}$ and $\alpha=0.3$. Figure 6 shows the temperature of the gas in contact with the wall $\left(\mathrm{T}_{\mathrm{nw}}\right.$, determined from the model) as a function of the average gas temperature, $T_{g_{\text {_aver }}}$, (determined experimentally, but in agreement with the model). The data fall onto a single line, independent of pressure.

$$
\mathrm{T}_{\mathrm{nw}} \approx \mathrm{T}_{\mathrm{w}}+0.28 .\left(\mathrm{T}_{\mathrm{g} \_ \text {aver }}-\mathrm{T}_{\mathrm{w}}\right)
$$

This allows the gas temperature near the wall to be estimated simply from measurements of the radiallyaveraged gas temperature, $\mathrm{T}_{\mathrm{g} \text {-aver }}$. Therefore in the analysis below we estimated the gas temperature in contact with the wall from this formula, using the average gas temperature determined from the $\mathrm{O}_{2}\left(\mathrm{~b}^{1} \Sigma_{\mathrm{g}}{ }^{+}\right)$ emission spectra observed perpendicular to the tube axis.

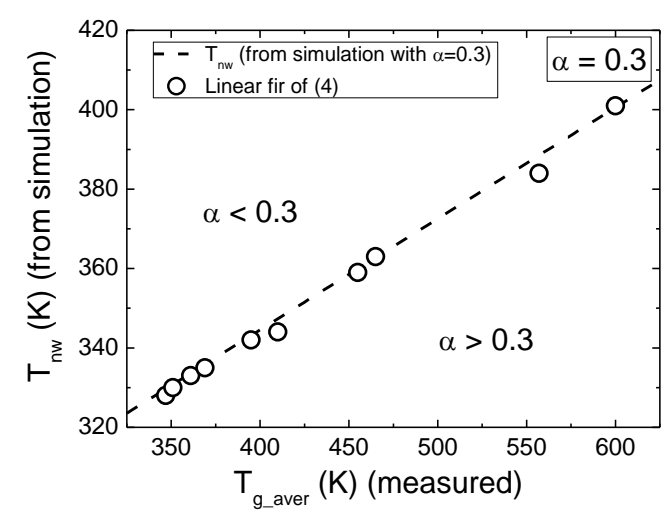

Figure 6. The gas temperature near the wall $\mathrm{T}_{\mathrm{nw}}$ (from the simulation, with an accommodation coefficient $\alpha=0.3$ ) as a function of the (experimentally-determined) radially-averaged gas temperature, $T_{\text {g-aver }}$ for the same nominal conditions. The data shown is for $\mathrm{T}_{\mathrm{w}}=+50^{\circ} \mathrm{C}$ with $\mathrm{J}_{\mathrm{d}}=10$ and $30 \mathrm{~mA}$. The dashed line is the linear fit $\mathrm{T}_{\mathrm{nw}} \approx \mathrm{T}_{\mathrm{w}}+0.28$. $\left(\mathrm{T}_{\mathrm{g} \_ \text {aver }}-\mathrm{T}_{\mathrm{w}}\right)$. 


\section{Measurement of the $O$ atom density, loss frequency and surface recombination probability}

The $\mathrm{O}$ atom loss frequency was determined from the temporal variation of the oxygen atom mole fraction, $[\mathrm{O}] / \mathrm{N}$ (where $\mathrm{N} \approx\left[\mathrm{O}_{2}\right]$ is the total gas density), during small $(\sim 15 \%)$ rectangular modulation of the discharge current. This is preferable to using the $\mathrm{O}$ atom density since in this case the effect of gas temperature variations on the total gas density, $\mathrm{N}$, are eliminated. The $[\mathrm{O}] / \mathrm{N}$ variations were followed by time-resolved actinometry, using Ar (added as 5\% of the gas flow) as the actinometer gas [1,3,4,6,911,13,35-42]. The effect of this small addition of Ar on the EEDF and other discharge parameters is negligible, since the EEDF is largely determined by electron collisions with the majority gas, $\mathrm{O}_{2}$ [43]. The conventional lines for $\mathrm{O}\left({ }^{3} \mathrm{P}\right)$ actinometry were used, namely $777 \mathrm{~nm}$ and $845 \mathrm{~nm}$ for $\mathrm{O}$ atoms, and $750 \mathrm{~nm}$ for $\operatorname{Ar}[1,3,4,13,17,35-40]$. The physical processes determining the optical emission intensities have been widely discussed previously $[1,4,11,13,17,37-40]$. Therefore we present only the final result the relation linking the $\mathrm{O}$ mole-fraction to the ratio of the intensities of the atomic emission lines $I_{O}$ and $I_{A r}$.

$$
\begin{aligned}
& \qquad \frac{\left[O\left({ }^{3} P\right)\right]}{N}=C_{A r}^{O} \cdot \frac{[A r]}{N} \frac{I_{O}}{I_{A r}}-\beta, \\
& \text { where } \quad \beta=\frac{k_{d e}^{O}}{k_{e}^{O}} \text {, and } \\
& \qquad C_{A r}^{O}=\frac{\sum_{j} A_{i j}^{O}+k_{q, O 2}^{O}\left[O_{2}\right]}{\sum_{m} A_{n m}^{A r}+k_{q, O 2}^{A r}\left[O_{2}\right]} \cdot \frac{S_{\lambda_{n m}}^{A r} A_{n m}^{A r}}{S_{\lambda_{i j}^{O}}^{A} A_{i j}^{O}} \cdot \frac{k_{e}^{A r}}{k_{e}^{O}}
\end{aligned}
$$

The actinometric coefficient $C_{A r}^{O}=C_{A r}^{O}\left(E / N ; P ; T_{g}\right)$ is a function of the discharge parameters. The term $\beta$ corrects for the contribution from electron-impact dissociative excitation of $\mathrm{O}_{2}$ molecules. $S_{\lambda}$ is the sensitivity of the detection system at wavelength $\lambda$. The radiative $\left(A_{i j}^{O}, A_{n m}^{A r}\right)$ and quenching $\left(k_{q, O 2}^{O}, k_{q, O 2}^{A r}\right)$ coefficients were taken from the literature [1,4,17,37-40]. Non-local radial effects on the EEDF can be ignored, since they only become important only when $\mathrm{pR} \leq 0.1$ Torr $\cdot \mathrm{cm}$ ( $\mathrm{p}$ is pressure, $\mathrm{R}$ is tube radius) $[41,42]$, so the local approximation can be used. The EEDF was calculated as a function of E/N using the Boltzmann equation and the MSU cross-section set for $\mathrm{O}_{2}$ [30], allowing the excitation rate constants to be calculated from the respective excitation cross sections $[4,40,44]$. At low pressure (where quenching can be neglected) $C_{A r}^{O}$ depends only on the ratio of excitation rate constants $\left(k_{e}^{A r}, k_{e}^{O}\right)$, which are functions of the EEDF, and therefore E/N. The calculations showed that the dissociative excitation term, $\beta$, can be neglected for the conditions studied here: $\beta<\left[\mathrm{O}\left({ }^{3} \mathrm{P}\right)\right] /[\mathrm{N}]$. Therefore the oxygen dissociative degree, $\left[\mathrm{O}\left({ }^{3} \mathrm{P}\right)\right] /[\mathrm{N}]$, is directly proportional to the line intensity ratio, $\mathrm{I}_{\mathrm{O}} / \mathrm{I}_{\mathrm{Ar}}$, provided that the coefficient $C_{A r}^{O}$ is constant.

The global balance of $\mathrm{O}\left({ }^{3} \mathrm{P}\right)$ atoms (both in the steady state and during current modulation) can be described by following equation:

$$
\frac{d\left(\int_{o}^{R}[O](r) \cdot 2 \pi r d r\right)}{d t}=\int_{o}^{R} P(r) \cdot 2 \pi r d r-2 \pi R \cdot[O]_{n w} \cdot \gamma_{O} \cdot \frac{v_{t h}}{4}-\int_{o}^{R} L(r) \cdot[O](r) \cdot 2 \pi r d r
$$

Here, $\mathrm{P}(\mathrm{r})$ and $\mathrm{L}(\mathrm{r}) \cdot[\mathrm{O}](\mathrm{r})$ are the total production and loss rates of $\mathrm{O}$ atoms by gas phase processes at radius $r, \gamma_{\mathrm{O}}$ is the surface loss probability of $\mathrm{O}$ atoms, $[\mathrm{O}]_{\mathrm{nw}}$ is the concentration of $\mathrm{O}$ atoms near the wall, and $v_{\mathrm{th}}$ is the thermal velocity of the gas in contact with the wall (at $\mathrm{r}=\mathrm{R}$ the tube radius), which has a temperature of $\mathrm{T}_{\mathrm{nw}}$. We assume that the mole fraction of oxygen atoms is constant across the radius (which is the case when the surface loss probability is small), and that atom loss in the axial direction is negligible (due to the long distance to the ends of the tube). Thus the thermal velocity is given by:

$$
v_{t h}=\sqrt{\frac{8 k T_{n w}}{\pi M_{O}}},
$$


where $M_{O}$ is the mass of an $\mathrm{O}$ atom. Equation (8) can be rewritten in terms of volume-averaged values (hereafter referred by the index "aver"), dividing by the tube cross-section area $\left(=\pi \mathrm{R}^{2}\right)$ we obtain an expression for the effective loss frequency of $\mathrm{O}$ atoms, $v_{\text {loss }}^{O}$ :

$$
v_{\text {loss }}^{O}=-\frac{1}{[O]_{\text {aver }}} \frac{d[O]_{\text {aver }}}{d t}=-\frac{P_{\text {aver }}}{[O]_{\text {aver }}}+\frac{[O]_{\text {nw }}}{[O]_{\text {aver }}} \cdot \gamma_{O} \cdot \frac{v_{\text {th }}}{2 R}+L_{\text {aver }},
$$

where

$$
[O]_{\text {aver }}=\left(\int_{o}^{R}[O](r) \cdot 2 \pi r d r\right) / \pi R^{2}
$$

and

$$
L_{\text {aver }}=\left(\int_{o}^{R} L(r) \cdot[O](r) \cdot 2 \pi r d r\right) /\left([O]_{\text {aver }} \cdot \pi R^{2}\right)
$$

Under conditions of small surface loss probability, $\gamma_{\mathrm{O}}$, and/or fast radial diffusion of $\mathrm{O}$ atoms, the atomic mole fraction, $[\mathrm{O}](\mathrm{r}) / \mathrm{N}(\mathrm{r})$, will be nearly constant across the radius (the gradient $\mathrm{d}([\mathrm{O}](\mathrm{r}) / \mathrm{N}(\mathrm{r})) / \mathrm{dr}$ is only a few percent for $\gamma_{\mathrm{O}} \sim 10^{-3}$ and pressure 5-10 Torr), i.e. $[\mathrm{O}](\mathrm{r}) / \mathrm{N}(\mathrm{r}) \approx[\mathrm{O}]_{\text {aver }} / \mathrm{N}$. During lowamplitude square-wave modulation (15-20\%) of the discharge current, the electron density will reach a new steady state much faster than the $\mathrm{O}$ atom density, causing a similar abrupt increase or drop of the electron concentration and, accordingly, of the production term $\mathrm{P}_{\text {aver }}$. The $\mathrm{O}$ atom mole fraction will relax after this abrupt increase or drop of the discharge current with the exponential time constant, $v_{\text {loss }}^{O}$. Rearranging equation (10), and assuming that $\mathrm{P}_{\mathrm{aver}}$ changes instantaneously gives us a formula that allows us to determine the recombination probability of $\mathrm{O}$ atoms, $\gamma_{\mathrm{O}}$, from the experimentally-observed loss frequency $v_{\text {loss }}^{O}$ :

$$
\gamma_{O}=\left(v_{\text {loss }}^{O}-L_{\text {aver }}\right) \cdot \frac{2 R}{v_{t h}} \cdot \frac{[O]_{\text {aver }}}{[O]_{n w}}
$$

If the temperature gradient is negligible, in the absence of significant gradients in the $\mathrm{O}$ atom density, $[\mathrm{O}]_{\mathrm{nw}}=[\mathrm{O}]_{\mathrm{aver}}$, and if gas-phase loss processes are neglected, equation (13) reduces to the wellknown formula:

$$
\gamma_{O}=v_{\text {loss }}^{O} \frac{2 R}{v_{t h}}
$$

For small values of the loss probability $\gamma_{O}$ (so that the $\mathrm{O}$ atom mole-fraction is constant across the radius), the $\mathrm{O}$ atom density profile follows the total gas density, which can be determined from the temperature profile and the ideal gas law, giving:

$$
\frac{[O]_{a v e r}}{[O]_{n w}}=\frac{T_{n w}}{R^{2}} \int_{0}^{R} \frac{2 r}{T(r)} d r,
$$

where $\mathrm{T}(\mathrm{r})$ and $\mathrm{T}_{\mathrm{nw}}$ are the gas temperature at radius $\mathrm{r}$ and near the wall, respectively. We evaluated this correction term using the modeled temperature profiles, giving a correction up to $30 \%$ in the value of $\gamma_{O}$ at the highest pressures and currents.

Now we must examine the possible gas-phase reactions that can cause oxygen atom loss (the term $\mathrm{L}_{\mathrm{aver}}$ in equation (13)) for our conditions, which include gas pressures up to 10 Torr. Ideally this term should be negligible or at least small compared to the total observed loss rate. The experiments were performed with low gas flow rates, leading to gas residence times longer than $1 \mathrm{~s}$, much longer than the lifetime of all transient species in the tube, so that transport due to flow can be neglected as a loss term. Studies carried out in the 60's [49,50] observed the loss of oxygen atoms in an $\mathrm{O}_{2}$ bath gas, and interpreted it as the recombination of $\mathrm{O}$ atoms with $\mathrm{O}_{2}$ as a third body: 


$$
\mathrm{O}+\mathrm{O}+\mathrm{O}_{2} \rightarrow \mathrm{O}_{2}+\mathrm{O}_{2}
$$

The generally-accepted rate constant of this three-body recombination is $\mathrm{k}_{\mathrm{O} 2}=3.34 \cdot 10^{-30} \cdot(1 / \mathrm{T}) \cdot \mathrm{e}^{-}$ $170 / \mathrm{T} \mathrm{cm}^{6} / \mathrm{s}[30,32]$. With this rate constant, we estimate a maximal $\mathrm{O}$ atom loss rate of $\sim 3-6 \mathrm{~s}^{-1}$ for 3-10 Torr and 30-40 mA, which is less than $\sim 10 \%$ of the total experimentally-observed loss rate (cf. figure 9). Oxygen atoms can recombine with $\mathrm{O}_{2}$ in three body collisions involving another $\mathrm{O}_{2}$ molecule, forming ozone,

$$
\mathrm{O}+\mathrm{O}_{2}+\mathrm{O}_{2} \rightarrow \mathrm{O}_{3}+\mathrm{O}_{2}
$$

This well-known reaction has a rate constant $\mathrm{k}_{\mathrm{O} 3}=5.96 \cdot 10^{-34} \cdot(300 / \mathrm{T})^{2.37} \mathrm{~cm}^{6} / \mathrm{s}$ [45]. Its impact will be most significant at the highest pressure (10 Torr), and the lowest currents (where the gas is cooler). Furthermore it will predominantly occur close to the wall, where the gas is cooler and denser. Any ozone produced will further react quickly with oxygen atoms,

$$
\mathrm{O}+\mathrm{O}_{3} \rightarrow \mathrm{O}_{2}+\mathrm{O}_{2}
$$

with a rate constant $\mathrm{k}=8 \times 10^{-12} \cdot \mathrm{e}^{-2080 / \mathrm{T}}\left[\mathrm{cm}^{3} / \mathrm{s}\right.$ ] [46], leading to the loss of two oxgen atoms overall. Ozone can also react with $\mathrm{O}_{2}\left(\mathrm{a}^{1} \Delta_{\mathrm{g}}\right)$ metastables,

$$
\mathrm{O}_{3}+\mathrm{O}_{2}\left(\mathrm{a}^{1} \Delta_{\mathrm{g}}\right) \rightarrow \mathrm{O}+2 \mathrm{O}_{2}(\mathrm{X})
$$

with a rate constant of $5.2 \cdot 10^{-11} \cdot \mathrm{e}^{-2840 / \mathrm{T}}\left[\mathrm{cm}^{3} / \mathrm{s}\right.$ ] [47]. Due to the high density of $\mathrm{O}_{2}\left(\mathrm{a}^{1} \Delta_{\mathrm{g}}\right)$ metastables in these discharges, this process can also be a significant loss channel for ozone at the highest pressures and currents. Finally, at high temperatures ozone can be dissociated,with a rate constant of $\mathrm{k}_{\mathrm{O} 3}{ }^{\text {dis }}=7.3 \cdot 10^{-10} \cdot \mathrm{e}^{-11435 / \mathrm{T}} \mathrm{cm}^{3} / \mathrm{s}$ [48] . However, the rate of this reaction is negligibly small for the temperatures occurring in this study. Due to the significant radial temperature gas density gradients present at the highest pressures and currents, it is difficult to make a simple estimation of the contribution of these reaction pathways involving ozone to the total oxygen atom loss rate. Therefore, we used the 1D(r) model described above, which indicated that even at 10 Torr these mechanisms account for less than $5 \%$ of the observed loss frequency.

At the lowest pressures $(<0.5$ Torr $)$ the associative detachment reaction

$$
\mathrm{O}+\mathrm{O}^{-} \rightarrow \mathrm{O}_{2}+\mathrm{e}
$$

with a rate constant $\mathrm{k}_{\mathrm{O}}=2 \cdot 10^{-10} \mathrm{~cm}^{3} / \mathrm{s}$ [50], can start to play a minor role in the volume loss of $\mathrm{O}$ atoms, but is still negligible $\left(<2 \mathrm{~s}^{-1}\right)$ compared to the total observed loss rate.

In conclusion, under the conditions studied here, gas phase losses are small (i.e. $\mathrm{L}_{\text {aver }}<<v_{\text {loss }}^{O}$ ), and oxygen atoms are predominantly lost by surface recombination. Previously reported loss probabilities for fused silica and glasses at room temperature $[1,4,8,9,11,17]$ are in the range $10^{-4}<\gamma_{0}<10^{-2}$, leading to characteristic loss times of a few tens of ms and above. The products of recombination at the wall are mainly $\mathrm{O}_{2}$ molecules, although a small amount of $\mathrm{O}_{3}$ can also be produced [17-20].

In addition to these (relative) kinetic measurements, equations (5-7) can also be used to estimate the absolute $\mathrm{O}$-atom mole-fraction, $\left[\mathrm{O}\left({ }^{3} \mathrm{P}\right)\right] / \mathrm{N}$. The accuracy of actinometry for absolute measurements has been tested mainly at lower pressures (below $\sim 1$ Torr) [37-40], when collisional quenching of the emitting states can be neglected, giving an estimated accuracy of 30-50\%. At the higher pressures studied here the accuracy is expected to be less good, due to radial variations of $\mathrm{E} / \mathrm{N}$, combined with uncertainties in the cross sections near threshold. Furthermore, collisional quenching becomes important, whereas the temperature variation of the quenching rate constants is poorly known. Thus we estimate the accuracy of absolute $[\mathrm{O}] / \mathrm{N}$ measurements to be good within a factor of two.

\section{Results and discussion}

Figure 7 a shows the time variation during the modulation period of the discharge current $J_{d}$, the gas temperature $\mathrm{T}_{\mathrm{g} \_ \text {aver }}$ and the reduced electric field $\mathrm{E} / \mathrm{N}$ at 0.75 Torr and $30 \mathrm{~mA}$. The current was measured directly, while $\mathrm{T}_{\mathrm{g} \_ \text {aver }}$ is estimated from the instantaneous measured power density using the (steady-state) dependency seen in figure 4 . This estimation is not valid during the first few $(\sim 3) \mathrm{ms}$ after the current step 
(marked by grey rectangles in figure 7a), during which time the gas temperature transitions to a new equilibrium value. These values of $\mathrm{T}_{\mathrm{g} \_ \text {aver }}$ are then used to calculate the total gas density $(\mathrm{N})$ from the ideal gas law and thus deduce the reduced field $(\mathrm{E} / \mathrm{N})$. The changes in $\mathrm{T}_{g_{-} \text {aver }}$ and $\mathrm{E} / \mathrm{N}$ during modulation are relatively small, because the electric field changes only slowly with current (figure 2). Moreover, the observed variations in E/N have an almost negligible effect on the actinometric coefficient (7). Our calculations show that, even in the worst case, $C_{A r}^{O}$ changes less than 1-2\% between the high- and lowcurrent phases. The emission intensity ratio therefore provides a reliable measurement of the time variation of the ratio $\left[\mathrm{O}\left({ }^{3} \mathrm{P}\right)\right] /[\mathrm{N}]$.

The temporal variation of the $\left[\mathrm{O}\left({ }^{3} \mathrm{P}\right)\right] / \mathrm{N}$ ratio during current modulation is shown in figure $7 \mathrm{~b}$, for 0.75 Torr and $30 \mathrm{~mA}$. The rise and decay curves are well-fitted by single exponential functions with time constants $\tau^{o n}$ and $\tau^{\text {off }}$ respectively. The time constants observed for the two oxygen lines $(777 \mathrm{~nm}$ and 845 $\mathrm{nm}$ ) and for the rise and fall are identical within $2 \%$, for all conditions studied. This observation demonstrates that: 1) the contribution of dissociative excitation to the $\mathrm{O}$ atom emission (which affects the $777 \mathrm{~nm}$ line far more than the $845 \mathrm{~nm}$ line [4]) is negligible; and 2) the $\mathrm{O}$ atom loss is caused by a firstorder process (a second order process would lead to a hyperbolic, a/t behavior, which is clearly incompatible with the form of the observed decay). For each set of discharge conditions the loss frequency, $v_{\text {loss }}^{O}=1 / \tau$, was taken to be the average of the four measurements, $v_{\text {loss }}^{O}=1 / 4\left(1 / \tau^{o n}{ }_{777}+1 / \tau^{o n}{ }_{845}+\right.$ $1 / \tau_{777}^{\text {off }}+1 / \tau^{\text {off }}{ }_{845}$ ). Furthermore, assuming the atoms are predominantly lost by surface recombination (discussed below), we can conclude that the surface loss probability does not change significantly during the modulation. The value of the $\left[\mathrm{O}\left({ }^{3} \mathrm{P}\right)\right] / \mathrm{N}$ ratio at different axial positions along the tube was also determined by actinometry. Only small variations were observed at the very ends of the plasma column, near the gas inlet and outlet.

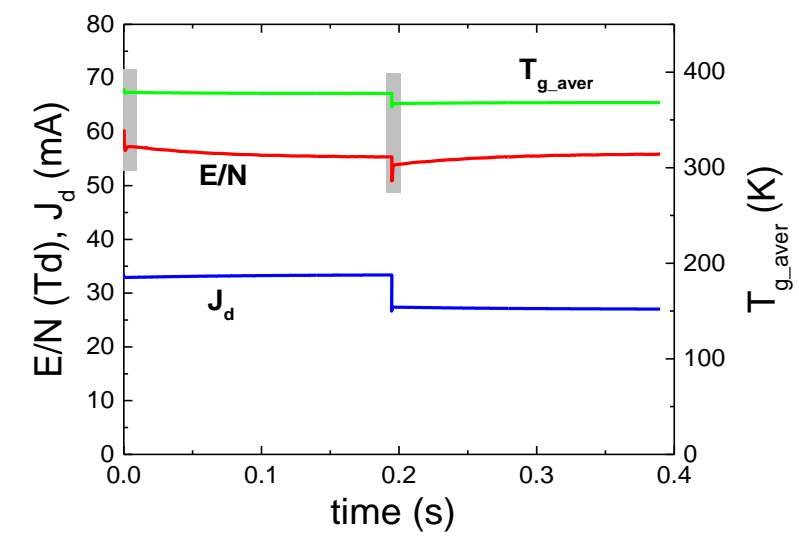

a)

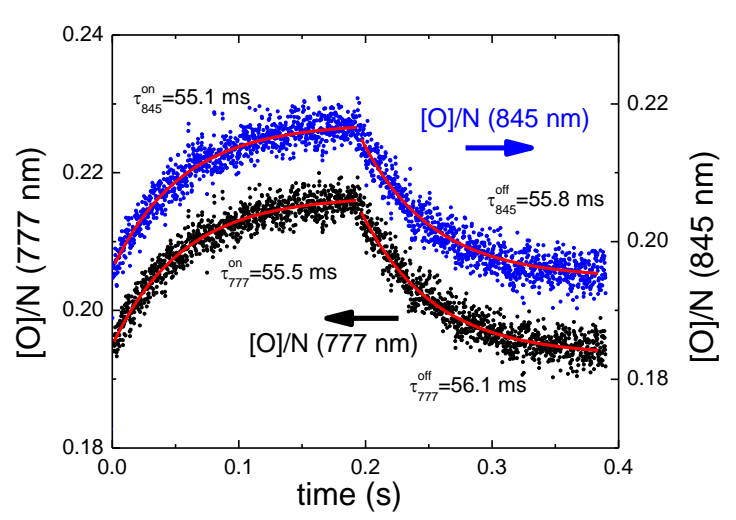

b)

Figure 7. a) Typical dynamics of the discharge current $\left(\mathrm{J}_{\mathrm{d}}\right)$, gas temperature $\left(\mathrm{T}_{\mathrm{g} \_a \text { aver }}\right)$ and reduced electric field $(\mathrm{E} / \mathrm{N})$ during discharge modulation at 0.75 Torr and $30 \mathrm{~mA}, \mathrm{~T}_{\mathrm{w}}=+50 \mathrm{C}$. The grey boxes indicate

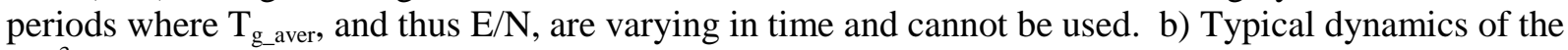
$\left[\mathrm{O}\left({ }^{3} \mathrm{P}\right)\right] / \mathrm{N}$ ratio during discharge current modulation at 0.75 Torr and $30 \mathrm{~mA}$, with $\mathrm{T}_{\mathrm{w}}=+50 \mathrm{C}$. Results are shown for both $777 \mathrm{~nm}$ and $845 \mathrm{~nm}$ lines of oxygen atoms. The red curves show exponential fits.

The measured loss frequency, $v_{\text {loss }}^{O}$, is presented as a function of pressure for different currents in figure 8 , for wall temperatures of $+5^{\circ} \mathrm{C}$ (a) and $+50^{\circ} \mathrm{C}(\mathrm{b}$ ). As the pressure is increased the loss frequency first decreases rapidly, passing through a minimum at around 0.75 Torr, before increasing steadily with pressure. The results are qualitatively similar for both wall temperatures, although the loss rate rises slightly faster with pressure for the lower surface temperature.

The $\mathrm{O}$ atom mole-fraction, $\left[\mathrm{O}\left({ }^{3} \mathrm{P}\right)\right] / \mathrm{N}$, and the oxygen atom density near the wall, $\left[\mathrm{O}\left({ }^{3} \mathrm{P}\right)\right]_{\mathrm{nw}}$, (calculated from $\left[\mathrm{O}\left({ }^{3} \mathrm{P}\right)\right] / \mathrm{N}$ and $\left.\mathrm{T}_{\mathrm{nw}}\right)$ are plotted in figure 9 . The oxygen atom mole fraction passes through a maximum at a pressure of $0.75-1$ Torr, the same pressure where the loss frequency is minimal. The oxygen atom density near the wall also passes through a broader maximum at a higher pressure (about 3-4 Torr), whose position varies only slightly with discharge current and wall temperature. At pressures above 1 Torr both the oxygen atom density and the mole fraction are both higher for higher wall 
temperatures. Note that trend of the incoming $\mathrm{O}$ flux is very similar to that of $[\mathrm{O}]_{\mathrm{nw}}$ shown in figure 9 , differing only by a factor of the square-root of the near-wall temperature, which increases by less than $20 \%$ over the pressure range considered.

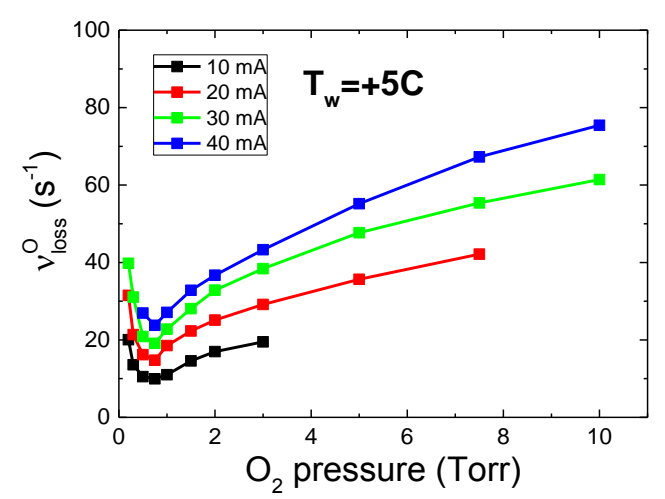

a)

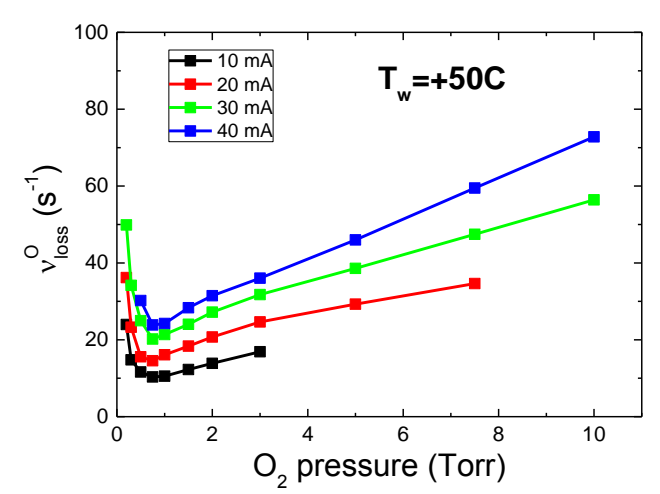

b)

Figure 8. a) Measured $\mathrm{O}$ atom loss frequencies $v_{\text {loss }}{ }^{o}$ at (a) $\mathrm{T}_{\mathrm{w}}=+5^{\circ} \mathrm{C}$ and (b) $\mathrm{T}_{\mathrm{w}}=+50^{\circ} \mathrm{C}$

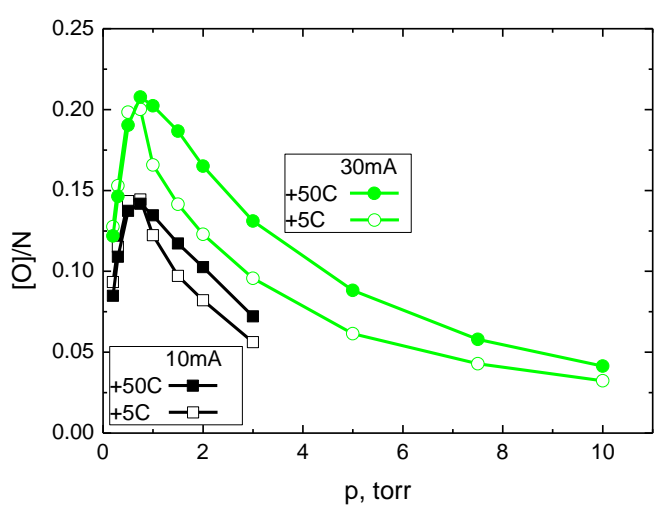

a)

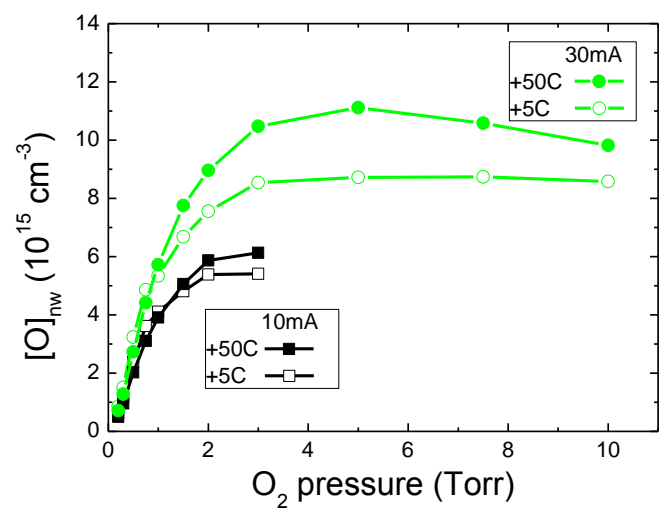

b)

Figure 9. a)The mole-fraction, $[\mathrm{O}] / \mathrm{N}$ and b) the $\mathrm{O}$ atom density near the wall $[\mathrm{O}]_{\mathrm{nw}}$ as a function of pressure for different currents, at wall temperatures $\mathrm{T}_{\mathrm{w}}=+5^{\circ} \mathrm{C}$ and $+50^{\circ} \mathrm{C}$, estimated from actinometry and $\mathrm{T}_{\mathrm{nw}}$ measurements.

The $\mathrm{O}\left({ }^{3} \mathrm{P}\right)$ atom loss probability $\gamma_{\mathrm{O}}$ was calculated from $v_{\text {loss }}^{O}$ using expressions (13) and (15). To correct for the effect of volume losses, the average volume loss rate $\mathrm{L}_{\text {aver }}$ was assumed to come only from the three-body recombination of two $\mathrm{O}$ atoms (the fastest volume loss process), giving a correction of $v_{\text {loss }}^{O}$ of up to a few percent. The data shown in figure 8 clearly show that $v_{\text {loss }}^{O}$ is a function of pressure and current, and is not simply a function of the wall temperature, which was kept constant at either $50 \mathrm{C}$ or 5 $\mathrm{C}$ during the measurements. The O-atom loss frequency increases with the discharge current for all pressures, while with gas pressure it passes through minimum in the region 0.5-1 Torr. This behavior can be explained by an Eley-Rideal (ER) surface recombination mechanism, in which $\mathrm{O}$ atoms arriving from the gas phase react with $\mathrm{O}$ atoms adsorbed on the surface. The kinetic energy of the incident $\mathrm{O}$ atoms, which varies with pressure and current, provides the activation energy for the reaction. The recombination rate in an ER mechanism depends on the surface density of adsorbed atoms (determined by the adsorption-desorption balance) and an Arrhenius factor depending on the temperature and an activation energy. In this case, "temperature" should refer to the average energy of the colliding (i.e. the incident and the adsorbed) atoms, and not simply the surface temperature (as assumed in previous studies). Since the wall temperature is fixed, any change in the energy available to overcome the recombination activation barrier must come from the kinetic energy of the incident $\mathrm{O}$ atoms, which are hotter than the wall due to gas heating in discharge, which increases with both gas pressure and with discharge current. It should be also noted that the $\mathrm{O}$ atoms will be in local thermal equilibrium with the $\mathrm{O}_{2}$ molecules even at the lowest pressure ( 0.2 Torr) since the average lifetime of $\mathrm{O}$ atoms, created hot by dissociation of $\mathrm{O}_{2}$, is 
significantly longer than the atom thermal equilibration time due to collisions with neutrals. This equilibration is confirmed by our model.

The values of the surface recombination probability, $\gamma_{0}$, derived from the measured values of $v_{\text {loss }}^{o}$ are plotted as a function of the inverse of the gas temperature near the wall in figure 10, for two values of the wall temperature, $+5^{\circ} \mathrm{C}$ and $+50^{\circ} \mathrm{C}$. Only data for pressures above 0.75 Torr are shown; the data for lower pressures (where the value of $\gamma_{0}$ rises again) will be discussed in section 7 . The values of $\gamma_{O}$ for each wall temperature fall onto a single curve, independent of discharge current and pressure. Such a grouping of $\gamma_{O}$ data onto a single curve (for a given surface temperature) is unlikely to be fortuitous and strongly suggests that $\mathrm{O}\left({ }^{3} \mathrm{P}\right)$ surface loss occurs through a mechanism that depends on the incident atom temperature, independent of the pressure and current.

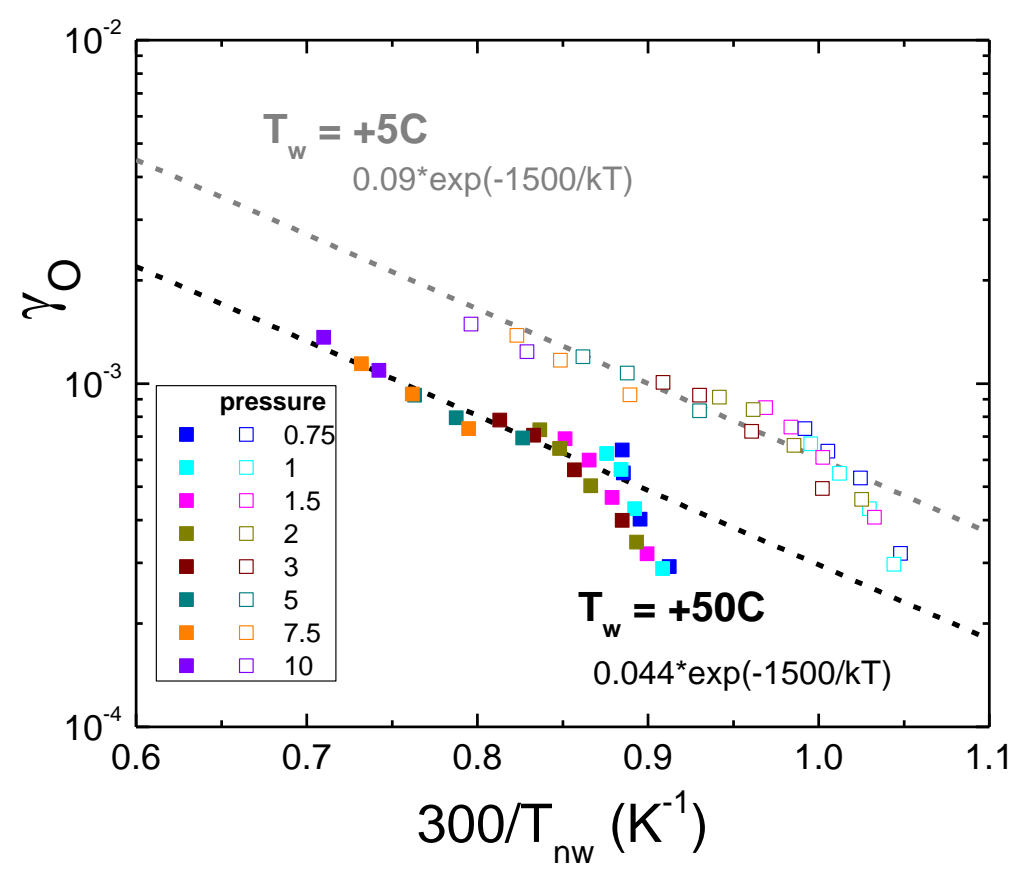

Figure 10. The $\mathrm{O}$ atom loss probability, $\gamma_{0}$, for "high" pressures ( $>0.5$ Torr) as a function of the inverse temperature of the $\mathrm{O}$ atoms incident on the tube wall $\left(\mathrm{T}_{\mathrm{nw}}\right)$. The data for all pressures (above 0.75 Torr) and currents are shown together. The open symbols correspond to a wall temperature $\mathrm{T}_{\mathrm{w}}=+5^{\circ} \mathrm{C}$, the full symbols correspond to $\mathrm{T}_{\mathrm{w}}=+50^{\circ} \mathrm{C}$. The dashed lines show fits to an Arrhenius formula (equation (16), with $\mathrm{E}_{\text {act }} \approx 0.13 \mathrm{eV}(1500 \mathrm{~K}), \mathrm{A}=0.09$ for $\mathrm{T}_{\mathrm{w}}=+5^{\circ} \mathrm{C}$ and $\mathrm{A}=0.044$ for $\mathrm{T}_{\mathrm{w}}=+50^{\circ} \mathrm{C}$.

In the conventional view of Eley-Rideal (ER) and Langmuir-Hinshelwood (LH) mechanisms [123], the atom surface loss probability depends only on the surface temperature, and this determines the relative importance of the two mechanisms. For ER recombination it has previously been assumed that the temperature in the Arrhenius law refers to the "wall temperature", and therefore that the "gas temperature very close to the wall" is equal to the "wall temperature" [52], although this distinction and its implications have not been discussed previously. In contrast, in the LH mechanism where O-atom loss occurs due to the recombination of two adsorbed atoms, one of which is a diffusing physisorbed atom, recombination by definition depends only on the wall temperature. Therefore, in the case of $\mathrm{LH}$ recombination the loss probability should be constant for a fixed surface temperature. However, our experiments show that $\gamma_{O}$ is not constant for a given surface temperature, but varies with the discharge conditions. Accordingly, the following conclusions can be drawn:

i. the observed variation implies an ER mechanism; this is to be expected since LH recombination is only significant for temperatures below $\sim 250 \mathrm{~K}[1,8,15,19-21])$.

ii. the observed variation of $\gamma_{O}$ is caused by changes in volume plasma parameters, notably the kinetic energy and flux of atoms arriving at the wall from the gas phase. Here we assume that, at these pressures above 0.75 Torr, the energy of ions striking the surface is too low to have an effect, see section 7).

The $\gamma_{O}$ data from figure 10 can be can be fitted to an Arrhenius law for both wall temperatures: 


$$
\gamma_{O}=A \cdot \exp \left(-\frac{E_{a c t}}{k T_{n w}}\right),
$$

These exponential fits are shown by dashed lines in figure 10, with the same activation energy for both cases, $E_{\text {act }}$, but with different pre-exponential factors, A. Such behavior is typical of an ER mechanism, but here it is the kinetic energy of incoming gas-phase atoms that overcomes the energy barrier, and not the surface temperature, as has been assumed previously $[1,8,15,19,20]$. Note that the data points for pressures below 2 Torr do not lie on the Arrhenius line; they are not included in the linear fit. A "knee" in the Arrhenius plot occurs exactly at the conditions (pressure and current) where the $\mathrm{O}\left({ }^{3} \mathrm{P}\right)$ density and the atomic flux to the wall are maximal (cf. figure 9b). The reasons for this inflection will be discussed below.

The $\mathrm{O}$ loss probabilities are higher when the wall temperature is lower, resulting in a higher preexponential factor. As the activation energy is the same, this shift of $\gamma_{O}$ can only be caused by an increase in the density of reactive sites at the surface. At these temperatures all chemisorption sites will be fully occupied [21,23], since atoms are irreversibly absorbed there. The desorption lifetime of chemisorbed atoms will be the order of tens or hundreds of minutes, and the frequency of surface recombination reactions is low, so that empty chemisorption sites will be quickly occupied by direct adsorption. Thus, the most reasonable explanation for this increase in $\gamma_{O}$ with decreasing wall temperature is additional ER recombination with physisorbed oxygen atoms, which will have higher surface density at lower wall temperatures.

The activation energy estimated here, $\mathrm{E}_{\mathrm{act}} \approx 0.13 \mathrm{eV}(\sim 1500 \mathrm{~K}$ or $\sim 12.5 \mathrm{~kJ} / \mathrm{mol})$, corresponds very well to the values observed in other experiments reported in the literature, which all fall in the range $0.155 \pm 0.026 \mathrm{eV}(\sim 1800 \pm 300 \mathrm{~K})[1,4,8,9,11,17]$, even though in this cases $\mathrm{E}_{\text {act }}$ was estimated by varying the surface temperature. To the best of our knowledge, the temperature of the atoms arriving at the surface has not been taken into account previously.

Note that, even for an ER mechanism, the behavior of the atom loss probability with temperature can be more complex than a simple Arrhenius law [17,23], since the atom surface loss probability also depends on the density of physisorbed atoms, which is determined by the sorption equilibrium, which depends on the incoming flux. Furthermore, the reactivity of each absorbed atom may depend on the details of its environment at the atomic level, which can lead to a distribution of activation and desorption energies for the different surface sites [52]. The observed deviations from a simple Arrhenius law can be caused by these effects, as detailed in the next section.

It should be noted that the $\gamma_{0}$ values measured at the lowest currents (i.e. at low gas temperature) are 2-4 times lower than those reported in previous papers under similar plasma conditions [1, 11]. Subsequent measurements carried out after the tube had been broken, repaired and annealed gave higher $\gamma_{0}$ values. However, with plasma operating time the value of gamma was observed to decrease slowly. It appears therefore that there is a slow evolution of the Pyrex surface with long exposure to an oxygen plasma, leading to passivation of some of the reactive chemisorption sites. This effect can be reversed by heating the Pyrex surface to a high temperature. A consequence of this lower density of chemisorption reaction sites on the passivated tube surface is that recombination via physisorbed atoms becomes significant, even at these relatively high surface temperatures and modest incident atom fluxes.

\section{Surface kinetics model for recombination at pressures above 0.75 Torr}

We propose a surface reaction model which complies with the conclusions from the previous section, namely:

i. $\quad$ atom surface recombination occurs through an Eley-Rideal mechanism;

ii. the recombination is activated by the kinetic energy of incident gas-phase $\mathrm{O}$ atoms;

iii. recombination with physisorbed ("weakly bonded") $\mathrm{O}$ atoms must be included in addition to chemisorbed atoms.

Several phenomenological models of ER surface recombination kinetics have been proposed, for example by Marinov et al. [23]. Such models are fitted to experimental data by the use of several adjustable parameters. Ideally, these parameters should have an obvious physical meaning, so that their values can be estimated from the experimental and theoretical literature. However, often the choice of parameters is rather arbitrary, varying widely between different studies and sometimes even exceeding reasonable physical limits. The aim of this work is to propose a phenomenological model that has been validated against well-defined experimental measurements of the atomic loss probabilities over a wide range of 
conditions. The number of adjustable parameters is typically of the order of 5 and, therefore, a large number of measurements is necessary to constrain the model and give confidence in the results. The current experiments provide such a benchmark, offering a careful characterization of the mechanism of $\mathrm{O}$ atom surface loss over a range of experimental conditions. They allow the development of a robust surface reaction model, with a small number of adjustable parameters and minimizing the arbitrariness of their values.

Before describing the elementary surface mechanisms in the model, it is worth discussing how the surface is described and introducing some definitions. An adsorbed atom can interact with the electronic structure of a surface in different ways. In the first case, a true chemical bond is formed, with a characteristic energy of a few eV [53]. This occurs at surface locations where the atom can come close enough to a surface atom (or group of atoms) to undergo a strong "electron-exchange" interaction, at a distance comparable with the distance between surface atoms. This is known as atom chemisorption and the active surface sites are denoted as chemisorption sites [1,5,14-19,21-23]. On clean metallic surfaces an atom can chemisorb almost anywhere, since free electrons from the metal are accessible. Considering only one monolayer of adsorbed atoms, the density of chemisorbed sites will be close to the density of surface metal atoms $\left(\sim 10^{15}-10^{16} \mathrm{~cm}^{-2}\right.$ depending on the metal phase and the surface roughness factor). However, if the metal surface is partly oxidized (which is often the case) the effective density of chemisorption sites is reduced. In the case of dielectric surfaces (such as Pyrex, as studied here) the chemical nature of the sites is quite different, and chemisorption usually only occurs at surface defects. This localized character of the interaction can lead to a wide variation of the density of chemisorption sites on dielectrics, typically from $\sim 10^{12}$ to $\sim 10^{14} \mathrm{~cm}^{-2}$ [54]. For semiconductors the situation is intermediate and the density of chemisorption sites can vary from what is typical for dielectrics up to that of metals. It should be noted that it is only possible to attain atomically clean surfaces in ultra-high vacuum conditions using special precautions; in real plasma experiments it is impossible. Moreover, disorder at the atomic level in amorphous materials also strongly influences chemisorption.

At longer distances the interaction between an ad-atom and the surface is weaker, resulting in an interaction energy below $\sim 0.5 \mathrm{eV}$ [53]. Such interactions only slightly disturb the electronic structure of the ad-atom and the surface, and do not change the chemical nature of the atom or of the surface. This type of interaction is known as physisorption. Physisorbed atoms are also sometimes referred to as "weakly bonded". Because of the long distance of the interaction, physisorbed atoms generally simultaneously interact several atoms in the substrate. Therefore, there are no specific sites for physisorption, in contrast to chemisorption. In this sense, a physisorbed atom can interact with any surface atom, and the maximal density of physisorbed atoms is limited by their packing density on the surface, which is comparable to the surface atom density $\left(\sim 10^{15}-10^{16} \mathrm{~cm}^{-2}\right.$, taking into account surface roughness).

In light of the discussion above, recombination at chemisorption sites can be described by

$$
\begin{gathered}
\mathrm{O}+\mathrm{Ch} \stackrel{k_{0}}{\longrightarrow} \mathrm{O}_{C h} \\
\mathrm{O}+\mathrm{O}_{\mathrm{Ch}} \stackrel{k_{R}^{C h}}{\longrightarrow} \mathrm{O}_{2}+\mathrm{Ch}
\end{gathered}
$$

where $O_{c h}$ and $C h$ represent a chemisorbed atom and a free chemisorption site, respectively. As was shown by Cartry et al. [5,14] and Lopaev et al. [17], under discharge conditions saturation of the chemisorption sites occurs very quickly, even with $\mathrm{O}$ atom densities as low as $\sim 10^{12}-10^{13} \mathrm{~cm}^{-3}$. For the experimental conditions studied here the $\mathrm{O}\left({ }^{3} \mathrm{P}\right)$ concentration is higher by at least two orders of magnitude and a full occupation of the chemisorption sites will occur in less than $10^{-4} \mathrm{~s}$ [23]. Therefore almost all chemisorption sites will be occupied by $\mathrm{O}$ atoms, $\left[\mathrm{O}_{\mathrm{ch}}\right]>>[\mathrm{Ch}]$ and $\left[\mathrm{O}_{\mathrm{ch}}\right] \approx\left[\mathrm{Ch}_{0}\right]$.

The rate coefficient for reaction (S2), $k_{R}^{C h}$, can be expressed in the usual Arrhenius form,

$$
k_{R}^{C h}=k_{0} \cdot P \approx k_{0} \cdot P_{0} \cdot \exp \left(-\frac{E_{a c t}^{C h}}{k T_{n w}}\right)
$$

where $\mathrm{T}_{\mathrm{nw}}$ is the temperature of the recombining atoms incident at the surface, $\mathrm{E}_{\mathrm{act}}{ }^{\mathrm{Ch}}$ is the activation energy for recombination with chemisorbed atoms, $\mathrm{P}$ is the elementary reaction probability that can be written in usual an Arrhenius form $P=P_{0} \cdot \exp \left(-E_{a c t}{ }^{C h} / k T_{n w}\right) . \mathrm{P}_{0}$ is a function of the properties of the surface 
and is often used as a fitting parameter in phenomenological models. $k_{0}$ is the collision frequency of gas phase atoms with chemisorbed atoms. $k_{0}$ is the effective collision frequency $\left(\mathrm{cm}^{2} \mathrm{~s}^{-1}\right)$ of gas phase atoms with chemisorbed atoms, which can be estimated as $k_{0} \sim a^{2} \cdot \mathrm{v}_{\mathrm{th}} . \mathrm{S} / \mathrm{V}$, where $a \approx 0.25 \mathrm{~nm}$ is the distance between surface atoms (so that $a^{2}$ is approximately the site area), $v_{\mathrm{th}}$ is the thermal velocity of $\mathrm{O}$ atoms, and $\mathrm{S} / \mathrm{V}=2 / \mathrm{R}$ is the surface to volume ratio of the discharge chamber, respectively. The flux of atoms undergoing ER recombination with chemisorbed atoms at the surface, $\Gamma_{\mathrm{Ch}}$, can be written as

$$
\Gamma_{C h}=k_{R}^{C h}\left[O_{C h}\right][O]_{n w} \cdot R / 2=\frac{\gamma_{O}^{C h} \cdot[O]_{n w} v_{t h}}{4}
$$

where $[\mathrm{O}]_{\mathrm{nw}}$ is the density of $\mathrm{O}\left({ }^{3} \mathrm{P}\right)$ atoms near the wall, from where the $\mathrm{O}$ atom loss probability due to reaction at chemisorption sites. Combining (17) and (18) gives:

$$
\gamma_{O}^{C h} \approx \frac{2 R}{v_{t h}} k_{0} P_{0}\left[C h_{0}\right] \cdot \exp \left(-\frac{E_{a c t}^{C h}}{k T_{n w}}\right)
$$

This expression for $\gamma_{O}^{C h}$ can explain the experimentally observed Arrhenius behavior of $\gamma_{O}$. However, it cannot explain the increase of $\gamma_{O}$ with decreasing wall temperature, since the number of chemisorbed sites is saturated, and therefore constant. As discussed above, $\mathrm{O}$ atoms can also recombine with physisorbed atoms, whose surface density will increase with decreasing temperature [21].

Similarly to chemisorption, the occupation of physisorption sites can be described by

$$
\begin{aligned}
& O+P h_{v_{d}^{P h}}^{\stackrel{k_{0}}{\longrightarrow}} O_{P h} \\
& O+O_{P h} \stackrel{k_{R}^{P h}}{\longrightarrow} O_{2}+P h
\end{aligned}
$$

where $P h$ and $O_{P h}$ correspond to a free physisorption site and a physisorbed $\mathrm{O}$ atom, respectively. Process $\mathrm{S} 3$ describes physisorption/desorption and $\mathrm{S} 4$ corresponds to $\mathrm{O}\left({ }^{3} \mathrm{P}\right)$ atom recombination with a physisorbed atom. The main difference from the mechanism involving chemisorption sites is that the surface density of physisorbed atoms is determined by an adsorption/desorption equilibrium, since the desorption energy is relatively low and the corresponding desorption rate is fast enough to depopulate most of the sites [21].

The rate coefficient for reaction (S4), ${k_{R}}^{P h}$, can be represented as before in the usual Arrhenius form,

$$
k_{R}^{P h}=k_{0} \cdot P_{0} \cdot \exp \left(-\frac{E_{a c t}^{P h}}{k T_{n w}}\right)
$$

where $T_{n w}$ is the temperature of the recombining atoms, $E_{\text {act }}{ }^{\mathrm{Ph}}$ is the activation energy for recombination with physisorbed atoms and $k_{0}$ and $\mathrm{P}_{0}$ are defined above. The frequency of $\mathrm{O}\left({ }^{3} \mathrm{P}\right)$ desorption from physisorption sites, $v_{\mathrm{d}}^{\mathrm{Ph}}$, is given by

$$
v_{d}^{P h}=v_{0} \cdot \exp \left(-\frac{E_{d}^{P h}}{k T_{w}}\right)
$$

where $v_{0} \approx 10^{13} \mathrm{~s}^{-1}$ corresponds to the vibration frequency of particles in the physisorption potential well, $T_{w}$ is the surface temperature and $E_{d}{ }^{P h}$ is the desorption energy for physisorbed $O$ atoms. The value of $v_{0}$ is often taken to be $10^{15} \mathrm{~s}^{-1}[5,7,8,21]$. A discussion of this value can be found in [55,56]. Here we assume 
a value of $10^{13} \mathrm{~s}^{-1}$, which is typical for the case of a single atom on a dielectric surface when $E_{d}>k_{w}$. Due to the high desorption rate around room temperature, the fractional occupation of physisorption sites only becomes comparable to that of chemisorption sites for very high incident fluxes of atoms. Under most conditions, the surface density of physisorbed atoms is significantly lower than the total density of physisorption sites, i.e. $\left[\mathrm{O}_{\mathrm{ph}}\right] \ll[\mathrm{Ph}]$. Since the rate of loss of physisorbed atoms by recombination is very small compared to the rate of desorption, the density of physisorbed atoms is defined by the equilibrium (S3), which can be written:

$$
\left[O_{P h}\right]=\frac{[O]_{n w}}{O_{f}}[P h]
$$

with $O_{f}=v_{d}^{P h} / k_{0} . O_{f}$ corresponds to the gas-phase $\mathrm{O}\left({ }^{3} \mathrm{P}\right)$ concentration necessary to cause occupation of half of the physisorption sites. Defining the total number of physisorption sites as $\left[\mathrm{Ph}_{0}\right]=[\mathrm{Ph}]+\left[\mathrm{O}_{\mathrm{Ph}}\right](\approx$ $\left.(3-10) \cdot 10^{15} \mathrm{~cm}^{-2}\right)$ and rearranging we get:

$$
[P h]=\frac{\left[P h_{0}\right]}{1+[O]_{n w} / O_{f}}
$$

Assuming a value of 0.3-0.4 eV for the $\mathrm{O}$ atom desorption energy, $\mathrm{E}_{\mathrm{d}}{ }^{\mathrm{Ph}}$, this concentration is rather high: $O_{f}>10^{16}-10^{17} \mathrm{~cm}^{-3}$. Therefore $[\mathrm{O}] \ll O_{f}$ for typical discharge conditions, including those reported here, and we can simplify this to:

$$
\left[O_{P h}\right] \approx \frac{[O]_{n w}}{O_{f}}\left[P h_{0}\right]
$$

and $\left[O_{P h}\right]<<\left[P h_{0}\right]$. The $\mathrm{O}$ atom recombination with physisorbed atoms in reaction $\mathrm{S} 4$ can be described (as for $\mathrm{S} 2$ in the case of chemisorption) by

$$
k_{R}^{P h}\left[O_{P h}\right][O]_{n w l}=\gamma_{O}^{P h} \cdot \frac{[O]_{n w} v_{t h}}{4}
$$

leading to this expression for the loss probability with physisorbed atoms:

$$
\gamma_{O}^{P h} \approx \frac{2 R}{v_{t h}} k_{0} P_{0}\left[P h_{0}\right] \cdot \exp \left(-\frac{E_{a c t}^{P h}}{k T_{n w}}\right) \cdot \frac{[O]_{n w}}{O_{f}}
$$

The total loss probability of $\mathrm{O}$ atoms is then $\gamma_{O}=\gamma_{O}^{C h}+\gamma_{O}^{P h}$,

$$
\gamma_{O}=\frac{2 R}{v_{t h}} k_{0} P_{0}\left[C h_{0}\right] \cdot e^{-\frac{E_{a c t}^{C h}}{k T_{n w}}} \cdot\left(1+\frac{\left[P h_{0}\right]}{\left[C h_{0}\right]} \frac{[O]_{n w}}{O_{f}} e^{-\left(\frac{E_{a c t}^{P h}-E_{a c t}^{C h}}{k T_{n w}}\right)}\right)=\gamma_{O}^{C h}\left(1+\frac{\left[P h_{0}\right]}{\left[C h_{0}\right]} \frac{[O]_{n w}}{O_{f}} e^{-\left(\frac{E_{a c t}^{P h}-E_{a c t}^{C h}}{k T_{n w}}\right)}\right)
$$

Regarding the values of the activation energies, $\mathrm{E}_{\mathrm{act}}^{\mathrm{Ch}}$ and $\mathrm{E}_{\mathrm{act}}{ }^{\mathrm{Ph}}$, let us consider two limiting cases. In the first one, denoted "case 1", we assume that the activation energies for ER recombination are the same for both chemi- and physisorbed $\mathrm{O}$ atoms, i.e. $\mathrm{E}_{\mathrm{act}}^{\mathrm{Ch}}=\mathrm{E}_{\mathrm{act}}^{\mathrm{Ph}}=\mathrm{E}_{\text {act }}$. From a physical point of view, this means that the activation energy depends only on the interaction between the adsorbed atom and the gas phase atom, and is independent of the nature of the bond between the adsorbed atom and the surface. This is in contrast with the idea presented by Kim and Boudart [8] and reviewed by Guerra [21] that the activation energy for recombination is related to the binding energy between the adsorbed atom and the wall. Expression (27) for $\gamma_{O}$ then simplifies to

$$
\gamma_{O}=\gamma_{O}^{C h}\left(1+\frac{\left[P h_{0}\right]}{\left[C h_{0}\right]} \frac{[O]_{n w}}{O_{f}}\right)
$$


In the second scenario, denoted as "case 2", ER recombination with physisorbed atoms is considered to be similar to volume three-body recombination, which has zero activation energy, with the surface playing the role of the third body. A similar assumption was discussed by Marinov et al. [23] for the case of LH recombination between physisorbed atoms, although the conceptual differences between both cases are subtler for ER than for LH. Indeed, the two cases explored here correspond to idealized limiting cases. The actual microscopic picture may be more complex and may also involve a two-step mechanism, where a gas phase atom is first physisorbed very close to another physisorbed atom, diffuses (overcoming an energy barrier) and then recombines. Future experiments under different operating conditions (e.g., at very low surface temperatures) combined with microscopic Monte-Carlo simulations could clarify this question.

In "case 2", the expression (27) for $\gamma_{0}$ becomes:

$$
\gamma_{O}=\gamma_{O}^{C h}\left(1+\frac{\left[P h_{0}\right]}{\left[C h_{0}\right]} \frac{[O]_{n w}}{O_{f}} e^{\frac{E_{a c t}}{k T_{n w}}}\right)
$$

In expressions (28) and (29), the dependence on discharge parameters appears through the $\mathrm{O}\left({ }^{3} \mathrm{P}\right)$ atom density near the wall $[\mathrm{O}]_{\mathrm{nw}}$ as well as through the activation energy terms in $\gamma_{O}^{C h}$ and $O_{f}$, which depend exponentially on $\mathrm{T}_{\mathrm{nw}}$ and $\mathrm{T}_{\mathrm{w}}$ respectively (see equations (20) and (21)). This causes $\gamma_{O}$ to vary with discharge current and pressure, in addition to varying with surface temperature.

Expressions (28) and (29) were used to fit the observed $\mathrm{O}\left({ }^{3} \mathrm{P}\right.$ ) surface loss probabilities, $\gamma_{\mathrm{O}}$, (at pressures above 0.75 Torr) using the measured $\left[\mathrm{O}\left({ }^{3} \mathrm{P}\right)\right] / \mathrm{N}$ ratio and the gas temperature near the wall. The results are shown in figure 11a and $11 \mathrm{~b}$, and the derived parameters are presented in Table 1 . As can be seen by comparing the model results in figure 11 to the measurements (figure 10), both models reproduce the general observed trends of $\gamma_{O}$ with the discharge parameters pressure, current and wall temperature. The linear behavior of $\gamma_{O}$ at pressures above $\sim 2$ Torr (left side of the graphs) is explained by the Arrhenius form of the recombination probability with an activation energy $\mathrm{E}_{\text {act }}$. Deviations from this behavior at lower pressures are caused by the terms in brackets in (28) and (29), which account for recombination with weakly bonded physisorbed atoms, whose concentration depends on both the $\mathrm{O}$ atom flux and the surface temperature. This model therefore explains the experimentally-observed deviations from the Arrhenius plots ("knees" of different amplitudes) at the conditions (pressure and current) where the $\mathrm{O}\left({ }^{3} \mathrm{P}\right.$ ) flux to the wall is maximal. The inflection is more pronounced at the lower wall temperature, since in this case the surface density of physisorbed atoms will be higher for the same atom flux. The variation of the oxygen atom flux with pressure and current depends on the near-wall atom density (figure 9b), multiplied by the mean kinetic velocity. However, the latter factor depends on the square root of the (near-wall) temperature, which only varies in the range $330-390 \mathrm{~K}$ (at $\mathrm{T}_{\text {wall }}=50 \mathrm{C}$ ), so the relative trend in flux is very similar to the density trend shown in figure $9(\mathrm{~b})$.

Table 1. Model parameters used for $\gamma_{0}$ calculation.

\begin{tabular}{|l|c|c|}
\hline Model parameter & $\begin{array}{c}\text { Case "1" (figure 11a): } \\
\mathbf{E}_{\text {act }}^{\mathbf{C h}}=\mathbf{E}_{\text {act }}^{\text {Ph }}=\mathbf{E}_{\text {act }}\end{array}$ & $\begin{array}{c}\text { Case "2" (figure 11b): } \\
\mathbf{E}_{\text {act }}^{\text {Ch }}, \mathbf{E}_{\text {act }}^{\text {Ph }}=\mathbf{0}\end{array}$ \\
\hline Activation energy $\mathrm{E}_{\text {act }}$ & $0.13 \mathrm{eV} / 1500 \mathrm{~K}$ & $0.163 \mathrm{eV} / 1900 \mathrm{~K}$ \\
\hline O atom desorption energy $\mathrm{E}_{\mathrm{d}}^{\mathrm{Ph}}$ & $0.302 \mathrm{eV} / 3500 \mathrm{~K}$ & $0.172 \mathrm{ev} / 2000 \mathrm{~K}$ \\
\hline Adsorption rate constant $\mathrm{k}_{0}\left(\mathrm{~cm}^{2} / \mathrm{s}\right)$ & $2 \times 10^{-10}$ & $2 \times 10^{-10}$ \\
\hline Reaction probability, $\mathrm{P}_{0}$ & 0.044 & 0.12 \\
\hline Chemisorption site density, $\left[\mathrm{Ch}_{0}\right]\left(\mathrm{cm}^{-2}\right)$ & $1.5 \cdot 10^{14}$ & $1.5 \cdot 10^{14}$ \\
\hline Physisorption site density, $\left[\mathrm{Ph}_{0}\right]\left(\mathrm{cm}^{-2}\right)$ & $10^{16}$ & $10^{16}$ \\
\hline
\end{tabular}




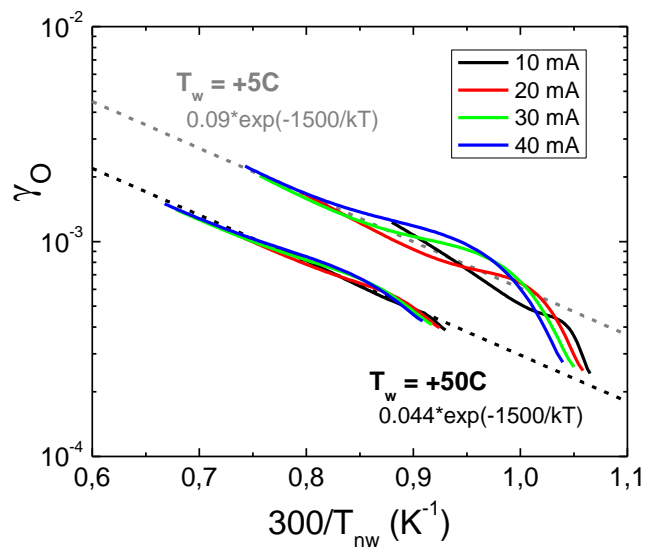

a)

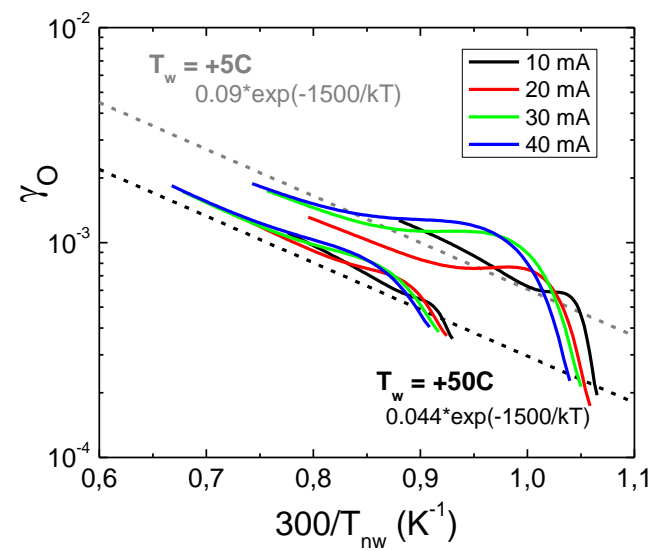

b)

Figure 11. Modelled behavior of $\gamma_{0}$ in cases "1" (a) and "2" (b), for the model parameters given in Table 1 , as a function of the inverse temperature of incident $\mathrm{O}$ atoms $\left(300 / \mathrm{T}_{\mathrm{nw}}\right)$ for different currents and wall temperatures $+5^{\circ} \mathrm{C}$ and $+50^{\circ} \mathrm{C}$. The dashed lines are fits by the simple Arrhenius formula (16), with $\mathrm{E}_{\mathrm{ac}} / \mathrm{k}=1500 \mathrm{~K}, \mathrm{~A}=0.09$ for $\mathrm{T}_{\mathrm{w}}=+5^{\circ} \mathrm{C}$ and $\mathrm{A}=0.044$ for $\mathrm{T}_{\mathrm{w}}=+50^{\circ} \mathrm{C}$.

It can be seen that the results from "case 1", where the activation barrier for ER recombination is the same for physisorbed and chemisorbed atoms, leads to a better agreement with the experimental data than "case 2", where there is no activation barrier for recombination with physisorbed atoms. It is also worth noting that the values of the model parameters determined here are comparable to those used in other works [1,5,17,21-23,45]. The activation energies for recombination, $\mathrm{E}_{\mathrm{act}}, 0.13 \mathrm{eV}$ in "case 1 " and $0.163 \mathrm{eV}$ in "case 2 ", compare well with the values $(\sim 0.155 \pm 0.025 \mathrm{eV})$ in the literature, $[1,4,8,9,11,17]$. The desorption energy for physisorbed $\mathrm{O}\left({ }^{3} \mathrm{P}\right)$ atoms, $\mathrm{E}_{\mathrm{d}}{ }^{\mathrm{Ph}}, 0.302 \mathrm{eV}$ in "case 1 " is only slightly higher than the desorption energy of physisorbed $\mathrm{O}_{2}(\sim 0.27 \mathrm{eV}$ [53]), which reinforces the view of a more physical than chemical character of the interaction between the weakly bonded atoms and the Pyrex surface. $\mathrm{E}_{\mathrm{d}}{ }^{\mathrm{Ph}}$ is almost double the value of $\mathrm{E}_{\text {act }}$, corresponding well to the generally accepted definition $1 / 2 \mathrm{E}_{\mathrm{d}}{ }^{\mathrm{O}} \approx \mathrm{E}_{\mathrm{D}} \approx \mathrm{E}_{\text {act }}$ for dielectrics, where $E_{D}$ is the energy barrier for diffusion $[1,5,8,17]$. Note that $E_{D}$ is considered to be equal to $\mathrm{E}_{\text {act }}$ by Lopaev et al. [17]. The value of $\left[\mathrm{Ph}_{0}\right]=10^{16} \mathrm{~cm}^{-2}$ is close to the density of surface atoms $\left(3 \cdot 10^{15} \mathrm{~cm}^{-2}\right)$ if we account for the surface roughness factor $\chi \sim 3-4$ for Pyrex, $\left[\mathrm{Ph}_{0}\right] \approx \chi \cdot 3 \cdot 10^{15} .\left[\mathrm{Ch}_{0}\right]=$ $1.5 \cdot 10^{14} \mathrm{~cm}^{-2}$ agrees well with the chemisorption site density on a Pyrex surface calculated from the $\mathrm{NO}_{2}$ surface production rate from $\mathrm{NO}$ recombination with chemisorbed $\mathrm{O}$ atoms [52].

It should be noted that the contribution of physisorbed atoms to ER recombination rate is quite small at $50^{\circ} \mathrm{C}$, since in this case the density of physisorbed atoms is lower than that of chemisorbed atoms, and "classical" ER recombination with chemisorbed atoms is dominant. Figure 12 shows the calculations, assuming case 1 , for $30 \mathrm{~mA}$ and both wall temperatures, $+50^{\circ} \mathrm{C}$ (a) and $+5^{\circ} \mathrm{C}$ (b) (see Table 1). When the wall temperature is decreased from $+50^{\circ} \mathrm{C}$ to $+5^{\circ} \mathrm{C}$, the contribution of ER recombination with physisorbed atoms increases and can even exceed that of chemisorbed atoms. At pressures below $\sim 1$ Torr (where the gas temperature is lowest, far right hand side of figure 12(b)) the reaction with chemisorbed atoms dominates over the physisorption component, due to the low $\mathrm{O}$ atom density. 


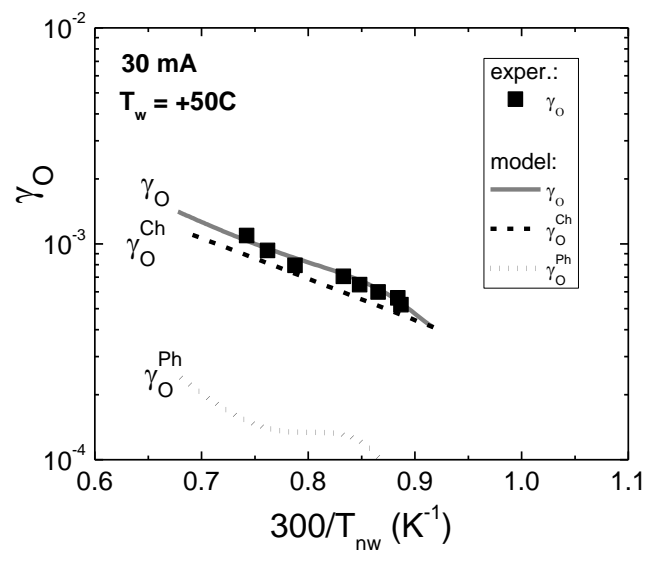

a)

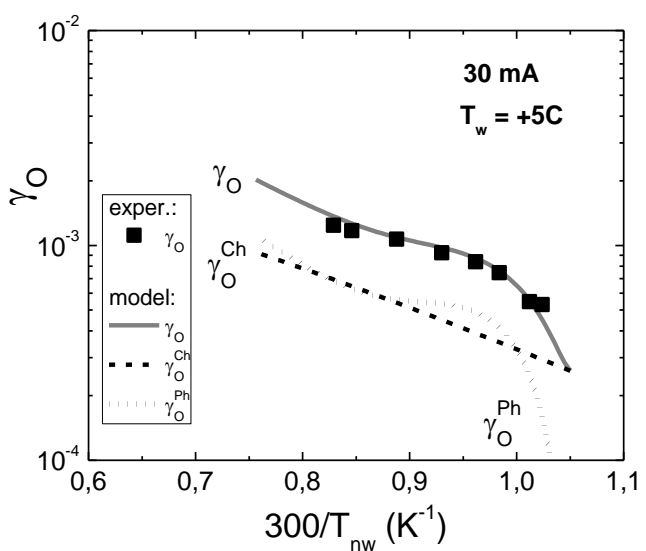

b)

Figure 12. The $\mathrm{O}$ atom surface loss probability $\gamma_{O}$ for $30 \mathrm{~mA}$ and wall temperatures $+50^{\circ} \mathrm{C}$ (a) and $+5^{\circ} \mathrm{C}$ (b) in case " 1 " as a function of the inverse temperature of $\mathrm{O}$ atoms $\left(300 / \mathrm{T}_{\mathrm{nw}}\right)$. The symbols correspond to experimental data, the dashed line is the contribution of chemisorbed atoms $\gamma_{O}^{C h}$ to the total loss probability and the dotted line is the contribution of physisorbed atoms $\gamma_{O}^{P h}$.

In contrast to the case of crystalline solids, for an amorphous surface the individual adsorption sites and their corresponding desorption and activation energies, $E_{d}$ and $E_{a c t}$, can exhibit significant variations. This has been demonstrated for $\mathrm{NO}_{2}$ formation from $\mathrm{NO}$ oxidation with adsorbed $\mathrm{O}$ atoms by Guerra et al. [52]. The distribution of physisorption energies may be wide enough to include "quasichemisorbed" atoms with bond energies around $1 \mathrm{eV}$. Adsorbed $\mathrm{O}$ atoms with $\mathrm{E}_{\mathrm{d}}$ in the range $\sim 0.3-0.7 \mathrm{eV}$ were observed by Guerra et al. [52]. The residence times of these "weakly bonded" atoms on a surface can vary from seconds to hundreds of seconds $[5,14]$ and they may play an essential role in surface recombination.

Guerra et al. [52] also showed that chemisorbed $\mathrm{O}$ atoms on Pyrex have a distribution of activation (and probably also desorption) energies, depending on the atom neighborhood. If the distribution is wide, only the low activation-energy "shoulder" will participate in recombination, since chemisorbed atoms requiring high activation energies will only react very slowly. In order to qualitatively model the effect of a distribution of activation energies on the $\mathrm{O}$ atom surface recombination, we have assumed a Gaussian distribution of surface-site activation energies,

$$
[C h]=\left[C h_{0}\right] \cdot \frac{1}{\sqrt{2 \pi}} \exp \left(-\frac{\left(E-E_{a c t}\right)^{2}}{2 \delta E_{a c t}^{2}}\right),
$$

where $E_{a c t}$ is the mean activation energy and $\delta E_{a c t}$ is the dispersion of the distribution. All other parameters are kept the same as before.

Figure 13 presents a series of model calculations (assuming case 1) for a current of $30 \mathrm{~mA}$ and various activation energy distributions according to equation (30). The mean value, $\mathrm{E}_{\text {act }}$, was varied for each given value of the width of the distribution, $\delta \mathrm{E}_{\text {act }}$, until the best agreement with the experimental data was achieved. The resulting distributions are presented in the insert to the figure. It can be seen that the calculations for $\delta \mathrm{E}_{\mathrm{act}} / \mathrm{k}<400 \mathrm{~K}$ all reproduce the experimental data, indicating that the distribution of activation energies does not exceed this value. In effect, in this model recombination will only occur at the most reactive sites, which represent only a small fraction of the total. Notice that the upper limit of the ratio $\delta \mathrm{E}_{\mathrm{act}} / \mathrm{E}_{\mathrm{act}}<\sim 1 / 5$ estimated here is wider than the spread of activation energies assumed by Guerra et al. [52].

The present results illustrate both the power and the limitations of phenomenological models for surface recombination. They show that exact values for activation energies and surface parameters extracted from these models must be used with care. Nonetheless, despite some arbitrariness in the determination of various parameters, realistic bounds can be established and the underlying "coarsegrained" mechanism ruling recombination can be established. For instance, the inflection on the $\gamma_{0} v s$. 
$\left(300 / \mathrm{T}_{\mathrm{nw}}\right)$ curves, seen in both experiment (figure 10) and the model calculations (figures 11, 12 and 13) can be ascribed to ER recombination with physisorbed atoms (reaction S4), a mechanism that can be considered to be clearly proved.

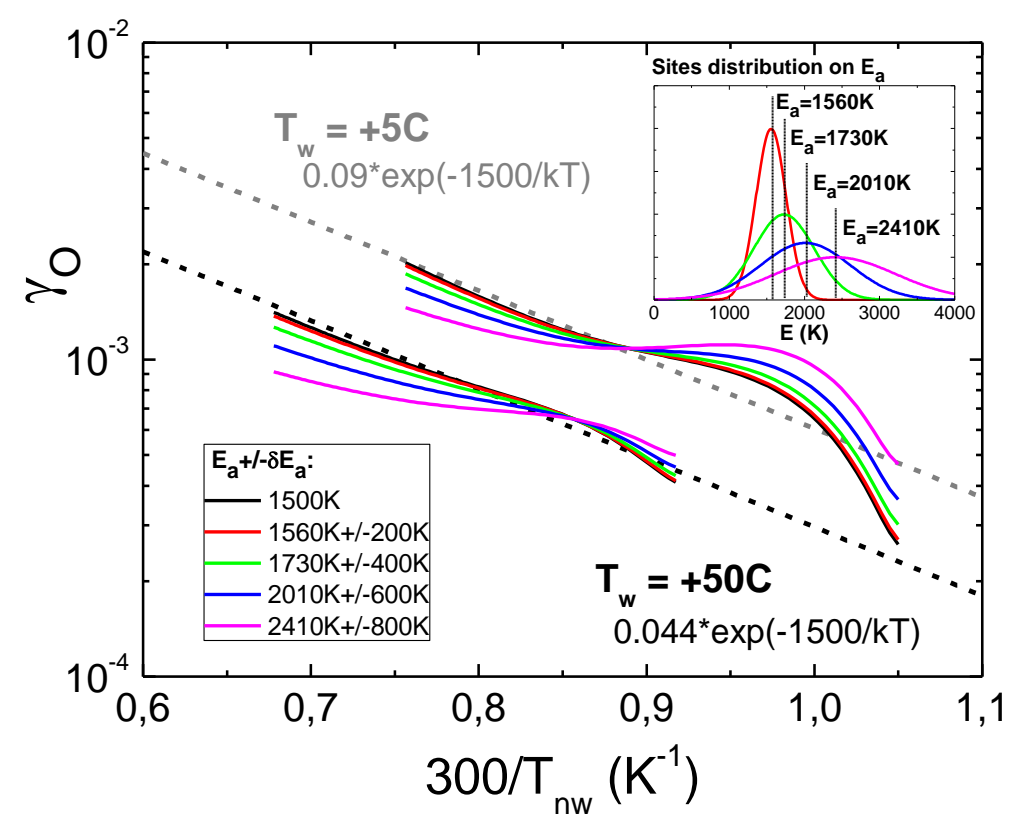

Figure 13. Calculated $\gamma_{O}$ as a function of reverse temperature of $O$ atoms $\left(300 / \mathrm{T}_{\mathrm{nw}}\right)$ for $30 \mathrm{~mA}$, for two surface temperatures $\left(\mathrm{T}_{\mathrm{w}}=+5^{\circ} \mathrm{C}\right.$ and $\left.+50^{\circ} \mathrm{C}\right)$ and different activation energy distributions $\left(\mathrm{E}_{\mathrm{a}}\right)$ defined by expression (29). The distributions are shown in the insert. The dashed lines correspond to the simple Arrhenius expression (16) with $\mathrm{E}_{\mathrm{act}} \approx 0.13 \mathrm{eV}(1500 \mathrm{~K}), \mathrm{A}=0.09$ for $\mathrm{T}_{\mathrm{w}}=+5^{\circ} \mathrm{C}$ and $\mathrm{A}=0.044$ for $\mathrm{T}_{\mathrm{w}}=$ $+50^{\circ} \mathrm{C}$.

\section{Recombination probability at pressures below 0.75 Torr.}

The variation of the $\mathrm{O}$ atom loss probability as a function of discharge current is shown in Figure 14, for pressures between 0.2 and 0.5 Torr. A strong increase with discharge current is observed, and the effect increases as the pressure is lowered. The effect is comparable for wall temperatures of both $+5^{\circ}$ and $+50^{\circ} \mathrm{C}$. Clearly these data points would not fit onto the curves of an Arrhenius plot, and thus cannot be explained by the ER model. This increase in the surface recombination probability correlates with increasing plasma density, and therefore increasing ion flux to the walls. As the pressure is lowered the plasma sheaths become less collisional, so the average energy of ions arriving at the wall increases. The $\mathrm{O}$ atom density is low under these conditions, so ER recombination with physisorbed atoms can be neglected. Therefore this increase in $\gamma_{O}$ must be caused by an increased density of chemisorption sites. This implies that new chemisorption sites are generated by ion bombardment at low pressure.

This increase in chemisorption sites could be due to modification of the Pyrex surface itself, or by surface cleaning, i.e. removal by ion bombardment of adsorbates occupying chemisorption sites. Such processes require bombardment by ions with a kinetic energy above the energy of a chemical bond (a few $\mathrm{eV}$ as minimum). 


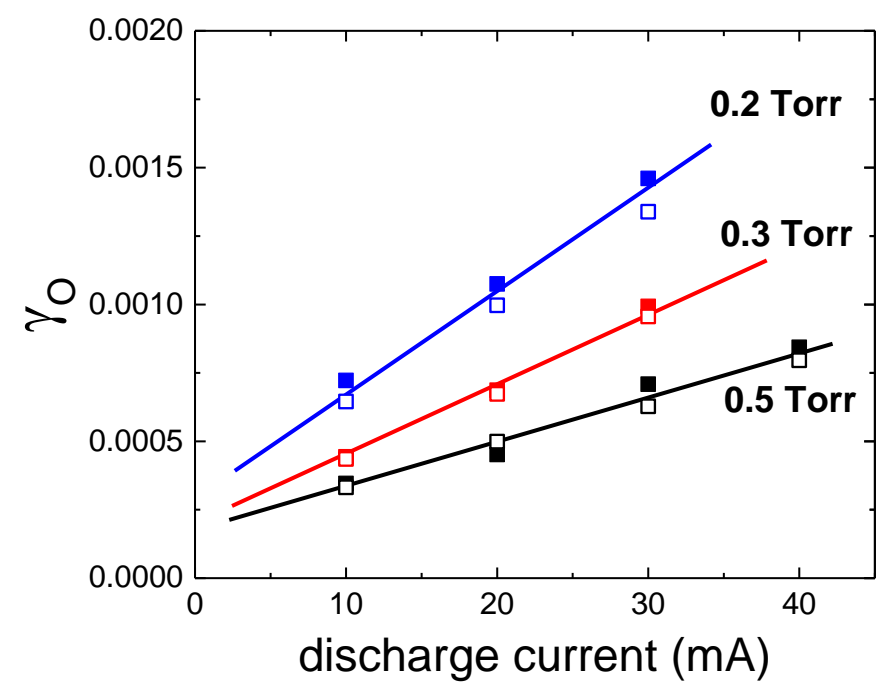

Figure 14. The $\mathrm{O}$ atom loss probability, $\gamma_{\mathrm{O}}$, for "low" pressures $(\leq 0.5$ Torr $)$ calculated using equation (13) as a function of discharge current. The full symbols are for a wall temperature $\mathrm{T}_{\mathrm{w}}=+50^{\circ} \mathrm{C}$, the open symbols for $\mathrm{T}_{\mathrm{w}}=+5^{\circ} \mathrm{C}$. The lines are linear fits of the data.

The energy distribution functions (IEDF) of ions arriving at the wall were calculated using a Monte-Carlo model for the ion transport through the plasma sheath in front of the wall. The potential drop across the sheath corresponds to the difference between plasma and floating potentials. This difference is always of the order of the ionization potential [57,58], since the creation rate of electrons in the bulk (requiring at least the ionization energy) must be equal to the ion flux leaving the plasma through the sheath to the floating walls. So, to estimate the IEDF at the wall a typical value of $\sim 1.5 \times \mathrm{O}_{2}$ ionization potential $(\sim 18 \mathrm{eV})$ was taken as the voltage drop across the sheath.

In our simple sheath model we assume that the ion flux comprises only $\mathrm{O}_{2}{ }^{+}$, and consider both elastic and charge-exchange collisions with $\mathrm{O}_{2}$ molecules. The $1 \mathrm{D}(\mathrm{r})$ model confirms that the ion flux to the surface is predominantly $\mathrm{O}_{2}^{+}$, the flux of $\mathrm{O}^{+}$only becoming significant at the lowest pressures (representing about $0.6 \%$ of the total ion flux at 1 Torr, rising to $15 \%$ at 0.3 Torr). For the sake of simplicity we only consider $\mathrm{O}_{2}{ }^{+}$ions our Monte Carlo model. The cross-sections for $\mathrm{O}_{2}{ }^{+}$were taken from Babaeva et al. [60]. Charge exchange collisions create fast $\mathrm{O}_{2}$ molecules, which are also traced in the simulation, and these also undergo elastic collisions with $\mathrm{O}_{2}$ until their kinetic energy approaches the bulk gas temperature. The sheath thickness $\mathrm{s}_{\mathrm{m}}$ was estimated from the radial distribution of charged species from the $\mathrm{O}_{2}$ discharge model (see section 3 ) as the region where charge separation becomes significant (more than 5\%: $\left.\left[\left(\mathrm{N}_{\mathrm{O} 2+}+\mathrm{N}_{\mathrm{O}+}\right)-\left(\mathrm{N}_{\mathrm{e}}+\mathrm{N}_{\mathrm{O}_{-}}+\mathrm{N}_{\mathrm{O} 2-}+\mathrm{N}_{\mathrm{O} 3-}\right)\right] /\left(\mathrm{N}_{\mathrm{O}_{+}+}+\mathrm{N}_{\mathrm{O}_{+}}+\mathrm{N}_{\mathrm{O}_{+}}\right)>0.05\right)$, giving $\mathrm{s}_{\mathrm{m}} \sim 0.1-$ $0.15 \mathrm{~cm}$ for $\mathrm{p}<1$ Torr. The $\mathrm{O}_{2} 1 \mathrm{D}(\mathrm{r})$ discharge model predicts a radial plasma density profile that is close to a classical Bessel radial profile, in agreement with simple dc discharge models. The plasma density at the plasma-sheath boundary was taken from this profile. This value was used for calculation of the initial ion flux in the Monte-Carlo model.

Figure 15a shows the energy distribution functions of ions and fast neutrals for a 30mA discharge at three pressures. The energy distribution functions of both ions and fast neutrals are close to Maxwellian, with a characteristic temperature that increases with decreasing pressure. The sheath is strongly collisional even at the lowest pressure $\left(0.2\right.$ Torr). The $\mathrm{O}_{2}{ }^{+}$ions undergo rapid charge-exchange collisions with $\mathrm{O}_{2}$ molecules in the sheath, creating a flux of fast neutrals arriving at the wall, $\mathrm{O}_{2}{ }^{\mathrm{f}}$, which is an order of magnitude greater than the ion flux even at 0.2 Torr. These fast molecules also undergo elastic collisions with $\mathrm{O}_{2}$, but nevertheless they still reach the wall with an energy distribution similar to that of the ions. The fraction of energetic particles (ions and fast neutrals) with an energy above thresholds $E_{\text {th }}$ of 3, 4.7 and $7.5 \mathrm{eV}$ are presented in Figure $15 \mathrm{~b}$. The total flux of energetic particles, $F_{\text {tot }}$, only varies slightly with pressure for a given current, having a value of $\mathrm{F}_{\mathrm{tot}} \sim(2.5-3) \cdot 10^{15}$ particles $/\left(\mathrm{cm}^{2} \mathrm{~s}\right)$ for $30 \mathrm{~mA}$ current and pressures $<1$ Torr.

The effect of these energetic particles on the surface will depend on their energy. Low-energy particles cannot modify or clean the surface. They will bring a heat flux, but the wall temperature is efficiently stabilized by the cooling system. In order to clean or modify the surface, i.e. to remove bulk or 
absorbed contaminant atoms, a particle must have a kinetic energy above the bond energy between the contaminant atom and surface or between surface atoms, corresponding to several $\mathrm{eV}$. The $\gamma_{0}$ data for low pressures is also presented in figure 15b. Between 1 Torr and 0.5 Torr the value of $\gamma_{0}$ hardly changes, but below 0.3 Torr the $\mathrm{O}$ atom loss probability increases significantly.

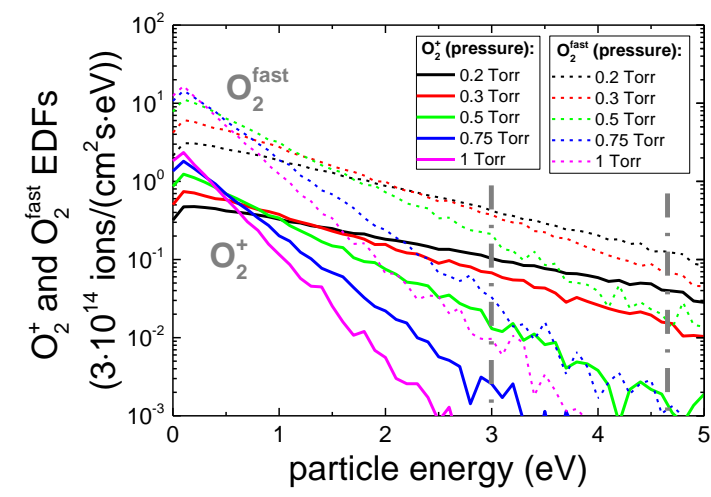

a)

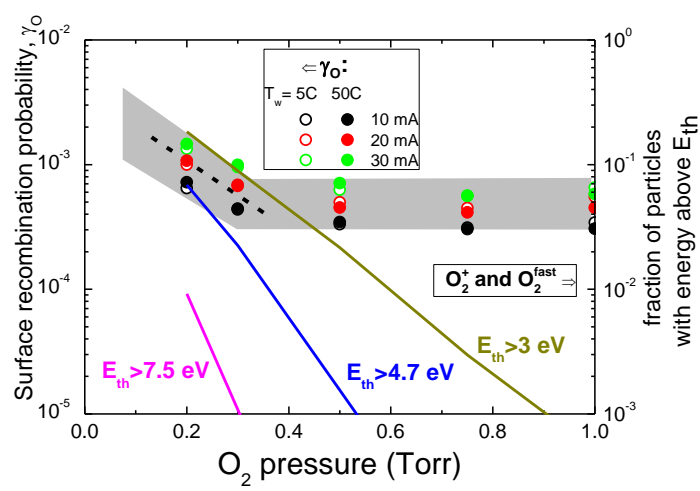

b)

Figure 15. a) The energy distribution functions of ions (solid lines) and fast neutrals (dashed lines) incident on the discharge walls at different pressures below 1 Torr. b) Surface recombination coefficient as a function of pressure $\left(\mathrm{T}_{\mathrm{w}}=+5^{\circ} \mathrm{C}\right.$ : full symbols, $\mathrm{T}_{\mathrm{w}}=+50^{\circ} \mathrm{C}$ open symbols), compared to the fraction of energetic particles $\left(\mathrm{O}_{2}{ }^{+}\right.$ions and fast neutrals $\left.\mathrm{O}_{2}^{\text {fast }}\right)$ having energy above thresholds $\mathrm{E}_{\mathrm{th}}:>3 \mathrm{eV}$, $>4.7 \mathrm{eV}$ and $>7.5 \mathrm{eV}$. The total flux of energetic particles, $\mathrm{F}_{\text {tot }}$, is almost constant with pressure, having a value $\sim(2.5-3) \cdot 10^{15}$ particles $/\left(\mathrm{cm}^{2} \mathrm{~s}\right)$ at $30 \mathrm{~mA}$. The dashed line shows the rate of increase of $\gamma_{O}$ with decreasing pressure.

The sputtering rate of amorphous $\mathrm{SiO}_{2}$ is expected to be small for the low ion energies occurring under these conditions. Nevertheless, even at floating potential (giving ion energies up to $\sim 10 \mathrm{eV}$, only slightly above the Si-O bond energy $(\sim 4.7 \mathrm{eV})$ ) some sputtering is possible. The generation of new chemisorption sites due to sputtering of surface atoms could, in principle, be the cause of the increase of the $\mathrm{O}\left({ }^{3} \mathrm{P}\right)$ surface loss probability. However the rate of increase in $\gamma_{0}$ at pressures below 0.3 Torr correlates with the increase of the fraction of energetic particles with energies above $\sim 3 \mathrm{eV}$. This energy is lower than the Si-O bond energy. This supports the view that surface cleaning, perhaps with some surface modification, is responsible for generating new adsorption sites, rather than sputtering. At the lowest pressures it is possible that $\mathrm{O}^{+}$ions may also play a role; these ions would bring higher chemical energy, allowing them to remove $\mathrm{O}$ atoms from the surface to form $\mathrm{O}_{2}$ molecules.

After exposure of a surface to the atmosphere, all chemisorption sites will generally be occupied. For hydrophilic surfaces (such as silica-based glasses) they are typically occupied by hydroxyl (OH) radicals, along with some hydrocarbons [54]. Whereas hydrocarbons can, as rule, be removed by cleaning procedures (for instance, by $\mathrm{O}_{2}$ plasma treatment), $\mathrm{OH}$ removal is difficult and requires high temperatures; under typical discharge conditions full $\mathrm{OH}$ surface coverage will be established. Therefore in typical low-pressure plasma chambers chemisorption sites on the walls are occupied mainly by $\mathrm{OH}$ groups, and partly by so-called coordinated water which can attach to these groups [54]. This has been confirmed by many surface analysis techniques (for instance, EPR and etc.).Temperatures above $~ 500^{\circ} \mathrm{C}$ are required to start removal of surface hydroxyl groups. The characteristic density of surface $-\mathrm{OH}$ groups estimated by different methods (EPR, IR absorbance) is $\sim(1-5) \cdot 10^{14}$ for silica-based glasses [54] and directly correlates with the density of chemisorption sites $[1,5,17,52]$.

If we assume that the active sites are predominantly $\mathrm{Si}-\mathrm{OH}$, with bond energies of $\mathrm{D}(\mathrm{Si}-\mathrm{O}) \approx 4.7$ $\mathrm{eV}$ and $\mathrm{D}(\mathrm{O}-\mathrm{H}) \approx 4.84 \mathrm{eV}$ (but maybe as low as $\sim 3-4 \mathrm{eV}$ depending on the surrounding environment [54]), we propose the following mechanism for the enhancement of $\mathrm{O}$ atoms surface loss by destruction of $\mathrm{Si}$ $\mathrm{OH}$ sites by energetic particles (ions or fast neutrals):

and/or

$$
\mathrm{Si}-\mathrm{OH}+\mathrm{O}_{2}^{+}\left(\text {or }_{2}{ }^{f}\right) \rightarrow \text { Si-O- + products }
$$

$$
\mathrm{Si}-\mathrm{OH}+\mathrm{O}_{2}^{+}\left(\text {or } \mathrm{O}_{2}{ }^{f}\right) \rightarrow \text { Si- }+ \text { products }
$$


The Si sites created by reaction S6 can then undergo radical addition:

$$
\mathrm{Si}-+\mathrm{O} \rightarrow \mathrm{Si}-\mathrm{O}-
$$

The Si-O- radical sites created can then catalyse $\mathrm{O}$ atom recombination through a cycle of two exothermic reactions:

$$
\begin{aligned}
& \text { Si-O- + O } \rightarrow \text { Si-O-O- } \\
& \text { Si-O-O- + O } \rightarrow \text { Si-O- + } \mathrm{O}_{2}
\end{aligned}
$$

Reaction S9 regenerates Si-O- sites for $\mathrm{O}$ atom ER recombination. The feasibility of this regeneration mechanism $\left(\mathrm{Si}-\mathrm{O}-\mathrm{O}-+\mathrm{O}^{3} \mathrm{P}\right)$ reaction on a model $\mathrm{SiO}_{\mathrm{x}}$ surface) was observed in static and dynamic DFT (density functional theory) calculations [61]. These DFT results will be reported in a separate paper. The regeneration mechanism for Si-O-O- sites has also been studied by Schwartzentruber et al. [62].

Since both the cleaning probability and the sputtering yield are expected to be very low $(<<1)$ for such low-energy particles, the required time for full cleaning or surface modification (i.e the characteristic generation time of "new sites") is expected to be rather long, probably exceeding tens or hundreds minutes even for 0.2 Torr. Therefore, over the characteristic timescale ( $\sim$ tens of minutes) of the present experiment (and indeed other studies) such processes can lead only to slow surface modification with the generation of new absorption sites. This is why the $\mathrm{O}\left({ }^{3} \mathrm{P}\right)$ surface loss probability (and therefore the observed loss frequency) increases with discharge current at low pressures, even though both the $\mathrm{O}$ atom density and the gas heating are small.

\section{Conclusion}

The surface recombination $\mathrm{O}\left({ }^{3} \mathrm{P}\right)$ atom was studied under well-controlled plasma conditions in a dc $\mathrm{O}_{2}$ discharge in a Pyrex tube. We found that the recombination probability is not simply a function of surface temperature and composition, but also depends on the characteristics of the plasma interacting with it. We demonstrate for the first time that gas heating in the discharge (with temperature-stabilized walls) causes an increase of the $\mathrm{O}\left({ }^{3} \mathrm{P}\right)$ surface loss probability. This dependence on incident atom energy rules out a Langmuir-Hinshelwood mechanism, in which recombining physisorbed atoms will have lost all memory of their incident energy. However, the results are well explained by an Eley-Rideal (ER) recombination mechanism, in which atoms from the gas phase recombine with adsorbed atoms on the surface and where the activation energy $(0.13 \mathrm{eV}(\sim 1500 \mathrm{~K}))$ for recombination comes from the kinetic energy of the incident atoms.

A phenomenological ER recombination model is proposed to interpret the measured $\mathrm{O}\left({ }^{3} \mathrm{P}\right)$ surface loss probabilities at pressures above 0.75 Torr. The model includes recombination of incident $\mathrm{O}$ atoms with both chemisorbed and weakly-bonded physisorbed atoms and is able to explain both the decrease in recombination probability with increasing surface temperature and the observed deviations from pure Arrhenius-law behavior. The observed $\mathrm{O}\left({ }^{3} \mathrm{P}\right)$ surface loss probabilities can be fitted equally well by model assuming a spread in the activation energy of up to $\delta \mathrm{E}_{\text {act }}< \pm 0.017 \mathrm{eV}( \pm 200 \mathrm{~K})$. The changes in behavior of $\mathrm{O}\left({ }^{3} \mathrm{P}\right)$ surface loss probability with pressure and current are caused by ER recombination with physisorbed atoms in addition to the chemisorbed atoms that are usually assumed. Changes in the absorption equilibrium of the physisorbed atoms induce changes in the $\mathrm{O}\left({ }^{3} \mathrm{P}\right)$ surface loss probability in addition to the changes in the kinetic energy of atoms incident on wall.

For pressures below 0.75 Torr the loss probability increases strongly as the pressure is lowered and the discharge current is increased. Discharge modeling and Monte-Carlo calculations of ion motion show that at pressures below $\sim 0.3$ Torr a significant fraction of ions and fast neutrals incident on walls have sufficient energy (few eV) to clean and/or modify the surface. Bombardment of the walls by energetic heavy particles leads to the generation of new adsorption sites and explains the increase of the 
loss probability with current. This effect appears to be reversible as soon as the ion flux is stopped (work in progress): interestingly, the $\gamma_{O}$ values at high pressure appear not to be affected by the history of the tube.

Models of low-pressure oxygen discharges should therefore take into account these effects on the atom surface loss rates. The use of simpler surface models or constant loss probability data taken from other experiments may lead to errors. This general conclusion is likely to be valid for other radicals in low-pressure plasmas with different chemistries.

\section{Acknowledgements}

This research was conducted in the scope of the KaPPA International Associated Laboratory (LIA), performed within the LABEX Plas@par project, and received financial state aid managed by the Agence Nationale de la Recherche, as part of the programme "Investissements d'avenir" under the reference ANR-11-IDEX-0004-02. It was also supported by the Applied Materials University Research Partnership Program. The Russian team is grateful to Russian Foundation of Basic Research (RFBR) for supporting this work (grant 16-52-16024). VG was partially supported by the Portuguese FCT, under Projects UID/FIS/50010/2013 and PTDC/FIS-PLA/ 1420/ 2014 (PREMiERE).

\section{References}

[1] P. Macko, P. Veis and G. Cernogora. "Study of oxygen atom recombination on a Pyrex surface at different wall temperatures by means of time-resolved actinometry in a double pulse discharge technique". Plasma Sources Sci.

Technol. 13 (2004) 251-262

[2] P. Vašina, V. Kudrle, A. Tálský, P. Botǒs, M. Mrázková and M. Měsko. "Simultaneous measurement of N and O densities in plasma afterglow by means of NO titration". Plasma Sources Sci. Technol. 13 (2004) 668-674

[3] D. V. Lopaev and A. V. Smirnov. "Diagnostics of Heterogeneous Processes with the Participation of Radicals by Time-Resolved Actinometry". Plasma Physics Reports 30 (2004) 882-893

[4] D. Pagnon, J. Amorim, J. Nahorny, M. Touzeau and M. Vialle. "On the use of actinometry to measure the dissociation in $\mathrm{O}_{2}$ DC glow discharges: determination of the wall recombination probability". J. Phys. D: Appl. Phys. 28 (1995) 1856-1868

[5] G. Cartry, L. Magne and G. Cernogora. Atomic oxygen recombination on fused silica: modelling and comparison to low-temperature experiments (300 K)". J. Phys. D: Appl. Phys. 33 (2000) 1303-1314

[6] A. Bousquet, G. Cartry and A. Granier. "Investigation of O-atom kinetics in $\mathrm{O}_{2}, \mathrm{CO}_{2}, \mathrm{H}_{2} \mathrm{O}$ and $\mathrm{O}_{2} / \mathrm{HMDSO}$ low pressure radiofrequency pulsed plasmas by time-resolved optical emission spectroscopy". Plasma Sources Sci. Technol. 16 (2007) 597-605

[7] B. Gordiets, C.M. Ferreira, J. Nahorny, D. Pagnon, M.Touzeau and M. Vialle. "Surface kinetics of N and O atoms in $\mathrm{N}_{2}-\mathrm{O}_{2}$ discharges". J. Phys. D: Appl. Phys. 29 (1996) 1021-1031

[8] Y.C. Kim and M. Boudart. "Recombination of O, N, and H Atoms on Silica: Kinetics and Mechanism". Langmuir 7 (1991) 2999-3005

[9] M. Balat-Pichelina, J.M. Badiea, R. Berjoana, P. Boubert. "Recombination coefficient of atomic oxygen on ceramic materials under earth re-entry conditions by optical emission spectroscopy". Chemical Physics 291 (2003) $181-194$

[10] A.D. Tserepi and T.A. Miller. "Spatially and temporally resolved absolute O-atom concentrations in etching plasmas". J. Appl. Phys. 77 (1995) 505-511

[11] J. Kristof, P. Macko, P. Veis. "Surface loss probability of atomic oxygen". Vacuum 86 (2012) 614-619 
[12] H. Nagai, M. Hiramatsu, M. Hori and T. Goto. "Measurement of oxygen atom density employing vacuum ultraviolet absorption spectroscopy with microdischarge hollow cathode lamp". REVIEW OF SCIENTIFIC INSTRUMENTS 74 (2003) 3453-3459

[13] G. Cartry, X. Duten and A. Rousseau. "Atomic oxygen surface loss probability on silica in microwave plasmas studied by a pulsed induced fluorescence technique”. Plasma Sources Sci. Technol. 15 (2006) 479-488

[14] G. Cartry, L. Magne and G. Cernogora. “Atomic oxygen recombination on fused silica: experimental evidence of the surface state influence”. J. Phys. D: Appl. Phys. 32 (1999) L53-L56

[15] M. Cacciatore, M. Rutigliano and G.D. Billing. "Eley-Rideal and Langmuir-Hinshelwood Recombination Coefficients for Oxygen on Silica Surfaces". JOURNAL OF THERMOPHYSICS AND HEAT TRANSFER 13 (1999) 195-203

[16] M. Cacciatore. "Some fundamental aspects of elementary gas-surface interactions”. Pure Appl. Chem. 71 (1999) 1809-1817

[17] D.V. Lopaev, E.M. Malykhin and S.M. Zyryanov. "Surface recombination of oxygen atoms in $\mathrm{O}_{2}$ plasma at increased pressure: I. The recombination probability and phenomenological model of surface processes". J. Phys. D: Appl. Phys. 44 (2011) 015201

[18] D.V. Lopaev, E.M. Malykhin and S.M. Zyryanov. "Surface recombination of oxygen atoms in $\mathrm{O}_{2}$ plasma at increased pressure: II. Vibrational temperature and surface production of ozone". J. Phys. D: Appl. Phys. 44 (2011) 015202

[19] D. Marinov, V. Guerra, O. Guaitella, J.-P. Booth and A. Rousseau. "Ozone kinetics in low-pressure discharges: vibrationally excited ozone and molecule formation on surfaces”. Plasma Sources Sci. Technol. 22 (2013) 055018

[20] D. Marinov, O. Guaitella, J.-P. Booth and A. Rousseau. "Direct observation of ozone formation on $\mathrm{SiO}_{2}$ surfaces in O2 discharges”. J. Phys. D: Appl. Phys. 46 (2013) 032001

[21] V. Guerra. "Analytical Model of Heterogeneous Atomic Recombination on Silicalike Surfaces". IEEE TRANSACTIONS ON PLASMA SCIENCE 35 (2007) 1397-1412

[22] Dynamical Monte Carlo simulation of surface atomic recombination. V. Guerra and J. Loureiro. Plasma Sources Sci. Technol. 13 (2004) 85-94

[23] D. Marinov, C. Teixeira, V. Guerra. "Deterministic and Monte Carlo methods for simulation of plasma-surface interactions (Review)”. Plasma Process Polym. 14 (2017)

[24] S.M. Zyryanov, D.V. Lopaev. "Measurements of the gas temperature in an oxygen plasma by spectroscopy of the $\mathrm{O}_{2}\left(\mathrm{~b}^{1} \Sigma_{\mathrm{g}}^{+}\right) \rightarrow \mathrm{O}_{2}\left(\mathrm{X}^{3} \Sigma_{\mathrm{g}}^{-}\right)$transition". Plasma Physics Report 33 (2007) 510-520

[25] P. Macko and P. Veis. "Time resolved $\mathrm{O}_{2}\left(\mathrm{~b}^{1} \Sigma_{\mathrm{g}}^{+}\right)$rotational temperature measurements in a low-pressure oxygen pulsed discharge. Simple and quick method for temperature determination". J. Phys. D: Appl. Phys. 32 (1999) 246250

[26] M. Touzeau, M. Vialle, A. Zellagui, G. Gousset, M. Lefebvre and M. Pealat. "Spectroscopic temperature measurements in oxygen discharges". J. Phys. D: Appl. Phys. 24 (1991) 41-47

[27] Hana Abada, Pascal Chabert, Jean Paul Booth, Jerome Robiche, G. Cartry. "Gas temperature gradients in a CF4 inductive discharge". J. Appl. Phys. 92 (2002) 422315

[28] A. D. Terekhov, E. N. Frolova, "Experimental comparison of methods of determining the thermal accommodation coefficient". Journal of Applied Mechanics and Technical Physics 13 (1972) 582

[29] J-P. Booth, D.Marinov, M Foucher, O. Guaitella, D. Bresteau, L. Cabaret and C Drag, J. Intrum. 10 (2015) C11003

[30] O.V. Braginskiy, A.N. Vasilieva, K.S. Klopovskiy, A.S. Kovalev, D.V. Lopaev, O.V. Proshina, T.V. Rakhimova, A.T. Rakhimov. "Singlet oxygen generation in $\mathrm{O}_{2}$ flow excited by rf discharge. I. Homogeneous discharge mode: $\alpha$-mode". J. Phys. D: Appl. Phys. 38 (2005) 3609-3625

[31] Ivanov V.V., Klopovsky K.S., Lopaev D.V., Mankelevich Y.A., Rakhimov A.T., Rakhimova T.V. "Structure and dynamics of a pulsed de discharge in pure oxygen". IEEE Transactions on Plasma Science $\mathbf{3 1}$ (2003) 528- 541 
[32] A.N.Vasiljeva, K.S.Klopovskiy, A.S.Kovalev, D.V.Lopaev, Y.A.Mankelevich, N.A.Popov, A.T.Rakhimov, T.V.Rakhimova. "On the possibility of $\mathrm{O}_{2}\left(\mathrm{a}^{1} \Delta_{\mathrm{g}}\right)$ production by a non-self-sustained discharge for oxygen-iodine laser pumping”. J.Phys. D: Appl. Phys. 37 (2004) 2455-2468

[33] Smith G.P., Golden D.M., Frenklach M., Moriarty N.W., Eiteneer B., Goldenberg M., Bowman C.T., Hanson R.K., Song C., Gardiner W.C., Jr, Lissianski V.V., Qin Z. GRI-Mech, http://www.me.berkeley.edu/gri-mech/

[34] H. Abada, P. Chabert, J.P. Booth, J. Robiche, G. Cartry. "Gas temperature gradients in a $\mathrm{CF}_{4}$ inductive discharge". J. Appl. Phys. 92 (2002) 4223-4229

[35] J. Conway, S. Kechkar, N.O’ Connor, C. Gaman, M.M. Turner and S. Daniels. "Use of particle-in-cell simulations to improve the actinometry technique for determination of absolute atomic oxygen density". Plasma Sources Sci. Technol. 22 (2013) 045004

[36] Studies of atomic oxygen in $\mathrm{O}_{2}+\mathrm{CF}_{4}$ rf discharges by two-photon laser-Induced fluorescence and optical emission spectroscopy. A. E. Walkup, K. L. Saenger, and G. S. Selwyn. J.Chem.Phys. 84 (1986) 2668-2674

[37] J. P. Booth, O. Joubert, J. Pelletier, and N. Sadeghi. “Oxygen atom actinometry reinvestigated: Comparison with absolute measurements by resonance absorption at 130 nm”. Journal of Applied Physics 69 (1991) 618-626

[38] H. M. Katsch, A. Tewes, E. Quandt, A. Goehlich, T. Kawetzki, and H. F. Döbele. "Detection of atomic oxygen: Improvement of actinometry and comparison with laser

Spectroscopy". Journal of Applied Physics 88 (2000) 6232-6238

[39] A. Granier, D. Chéreau, K. Henda, R. Safari, and P. Leprince. "Validity of actinometry to monitor oxygen atom concentration in microwave discharges created by surface wave in O2/N2 mixtures". Journal of Applied Physics 75 (1994) 104-114

[40] Lopaev D.V., Volynets A.V., Zyryanov S.M., Zotovich A.I., Rakhimov A. T. “Actinometry of O, N and F atoms". J. Phys. D: Appl. Phys. 50 (2017) 075202

[41] V.V. Ivanov, K.S. Klopovskiy, D.V. Lopaev, A.T. Rakhimov, and T.V. Rakhimova. "Nonlocal Nature of the Electron Energy Spectrum in a Glow-Discharge in Pure O2 : II. Actinometry of O $(3 P)$ Atoms in a Plasma at Low Gas Pressures". Plasma Physics Reports 26 (2000) 980-990

[42] K.S. Klopovskiy, D.V. Lopaev, O.V. Proshina, A.T. Rakhimov, and T.V. Rakhimova. "Effect of the Nonlocal Nature of the Electron Energy Spectrum on the Dissociation of Oxygen Molecules in a Discharge". Plasma Physics Reports 30 (2004) 542-548

[43] K.Kutasi, V. Guerra and P. A. Sá. "Theoretical insight into Ar- $\mathrm{O}_{2}$ surface-wave microwave discharges". $J$. Phys. D: Appl. Phys. 43 (2010) 175201

[44] J.E. Chilton, J.B. Boffard, R.S. Schappe and C.C. Lin. "Measurement of electron-impact excitation into the $3 p^{5} 4 p$ levels of argon using Fourier-transform spectroscopy". Phys. Rev. A 57 (1998) 267-277

[45] C. L. Lin and M. T. Leu, "Temperature and Third-Body Dependence of the Rate Constant for the Reaction O + $\mathrm{O}_{2}+\mathrm{M}-\mathrm{O}_{3}+\mathrm{M}$ '. International Journal of Chemical Kinetics 14 (1982) 417

[46] R. Atkinson, D. L. Baulch, R. A. Cox, J. N. Crowley, R. F. Hampson, R. G. Hynes, M. E. Jenkin, M. J. Rossi, and J. Troe. "Evaluated kinetic and photochemical data for atmospheric chemistry: Volume I - gas phase reactions of Ox, HOx, NOx and SOx species". Atmos. Chem. Phys. 4 (2004) 1461

[47] R. Atkinson, D. L. Baulch, R. A. Cox, R. F. Hampson Jr., J. A. Kerr, M. J. Rossi, J. Troe. "Evaluated Kinetic and Photochemical Data for Atmospheric Chemistry: Supplement VI. IUPAC Subcommittee on Gas Kinetic Data Evaluation for Atmospheric Chemistry”. Journal of Physical and Chemical Reference Data 26 (1997) 1329

[48] J. I. Steinfeld, S. M. Adler-Golden, and J. W. Gallagher, "Critical Survey of Data on the Spectroscopy and Kinetics of Ozone in the Mesosphere and Thermosphere". Journal of Physical and Chemical Reference Data 16 (1987) 911

[49] R. A. Young and R. L. Sharpless, J.Chem.Phys. 39 (1963) 1071.

[50] R. A. Young and G. Black, J.Chem.Phys. 44 (1966) 3741. 
[51] S G Belostotsky, D J Economou, D V Lopaev and T V Rakhimova. "Negative ion destruction by $\mathrm{O}\left({ }^{3} \mathrm{P}\right)$ atoms and $\mathrm{O}_{2}\left(a^{1} \Delta_{\mathrm{g}}\right)$ molecules in an oxygen plasma”. Plasma Sources Sci. Technol. 14 (2005) 532

[52] V. Guerra, D. Marinov, O. Guaitella and A. Rousseau. "NO oxidation on plasma pretreated Pyrex: the case for a distribution of reactivity of adsorbed O atoms". J. Phys. D: Appl. Phys. 47 (2014) 224012

[53] Bond G.C. 1989 Heterogeneous Catalysis Principles and Applications (Oxford University Press)

[54] Kiselev V.F., Kozlov S.N., Zoteev A.V. 1999 Introductory Solid Surface Physics (Moscow: Moscow State University Press)

[55] H. Ibach, W. Erley and H. Wagner 1980 "The preexponential factor in desorption-CO on Ni(111)" Surf. Sci. 92 $29-42$

[56] V. Guerra and D. Marinov 2016 "Dynamical Monte Carlo methods for plasma-surface reactions" Plasma Sources Sci. Technol. 26045001

[57] K.S. Klopovskiy, D.V. Lopaev, N.A. Popov, A.T. Rakhimov and T.V. Rakhimova. "Heterogeneous quenching of $\mathrm{O}_{2}\left({ }^{1} \Delta_{\mathrm{g}}\right)$ molecules in $\mathrm{H}_{2}: \mathrm{O}_{2}$ mixtures" J. Phys. D: Appl. Phys. 32 (1999) 3004-3012

[58] Yu B Golubovskii,I A Porokhova, J Behnke and J F Behnke. "A comparison of kinetic and fluid models of the positive column of discharges in inert gases". J. Phys. D: Appl. Phys. 32 (1999) 456-470

[59] A.A. Kudryavtsev, A.S. Smirnov and L.D. Tsendin, Physics of Glow Discharge. Lan', St.Petersburg, 2010, ISNN: 978-5-8114-1037-8

[60] N.Y. Babaeva, J.K. Lee, J.W. Shon and E.A. Hudson. "Oxygen ion energy distribution: Role of ionization, resonant, and non-resonant charge-exchange collisions”. J. Vac. Sci. Technol. A 23 (2005) 699-704

[61] E.N. Voronina, private communication

[62] T E Schwartzentruber, S Poovathingal, E C. Stern, 20th AIAA International Space Planes and Hypersonic Systems and Technologies Conference, 2015 - Glasgow, United Kingdom 